\title{
Studies for Better Treatment of Patients with Glioma
}

Annika Malmström

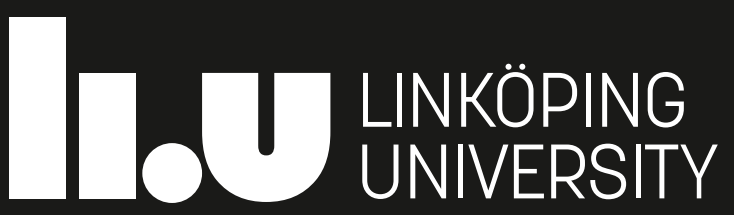




\title{
Studies for Better Treatment of Patients with Glioma
}

\author{
Annika Malmström
}

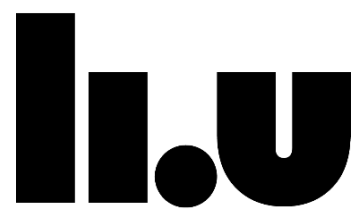

LINKÖPING UNIVERSITY

Faculty of Medicine and Health Sciences

Department of Clinical and Experimental Medicine

Division of Cell Biology 


\section{Main supervisor:}

Peter Söderkvist, PhD, Professor

Linköping University

\section{Co-supervisors:}

Marie Stenmark-Askmalm, MD, PhD, Assoc. Professor

Lund University

Roger Henriksson, MD, PhD, Professor

Umeå University

Marit Karlsson, MD, PhD, Assoc. Professor

Linköping University

(C) Annika Malmström, 2019

ISBN: 978-91-7929-979-8

ISSN: 0345-0082

Previously published papers I and II and additional material included in this thesis have been reprinted with permission of the copyright holder.

Paper III is included as Accepted Manuscript. This is a pre-copyedited, author-produced version of an article accepted for publication in Neuro-Oncology Practice following peer review. The version of record: Annika Malmström et al. Do we really know who has an MGMT methylated glioma? Results of an international survey regarding use of MGMT analyses for glioma. Neuro-Oncology Practice (2019) is available online at: https://doi.org/10.1093/nop/npz039. 
The capacity to blunder slightly is the real marvel of DNA. Without this special attribute, we would still be anaerobic bacteria and there would be no music.

Lewis Thomas, biologist, 1979

To Bosse and Kasper 



\section{Abstract}

In Sweden annually over 500 people will be diagnosed with the malignant brain tumor glioma. They are graded from I-IV. The majority are glioblastoma (grade IV) (GBM), these being the most aggressive type. Median survival for those treated with standard of care is expected to be around 15 months. This tumor will mainly affect those 60 years or older.

The studies in this thesis focus on treatment of patients with malignant gliomas grade III and IV. The aim of the studies is to improve the care of glioma patients. Papers I and II explored different therapeutic options in randomized trials, to facilitate individualized treatment recommendations. Findings from studies I and II, together with additional trials, demonstrated the importance of analyzing the tumor marker $O^{6}$-methylguanine DNA methyltransferase (MGMT) methylation status for survival of GBM patients treated with Temozolomide (TMZ). The third paper investigated how the analysis of this marker is implemented internationally.

The first study (paper I, Nordic trial) investigated treatment options for patients 60 years or older with GBM. The trial compared standard radiotherapy (SRT) over 6 weeks versus hypofractionated radiotherapy (HRT) over 2 weeks versus single agent TMZ administered in up to six 4 weekly cycles. In all, 342 patients were included in the trial. This study demonstrated that those randomized to TMZ had superior survival as compared to SRT. In addition, quality of life (QoL) data also suggested a better QoL for TMZ treatment than for radiotherapy. The benefit of TMZ treatment seemed to be limited to those with the tumor molecular marker MGMT methylated (inactivated).

The second trial (paper II, Neoadjuvant trial) studied whether integrating TMZ treatment with SRT for patients younger than 60 years with GBM (grade IV) and astrocytoma grade III would confer a survival benefit, if administered postoperatively, before the start of SRT (neoadjuvant). TMZ was provided for 2-3 four weekly cycles followed by SRT to patients randomized to neoadjuvant treatment and was compared to postoperative SRT alone. Although this trial could not illustrate any advantage of delaying the start of SRT while administering TMZ for the study cohort in general, for those included as astrocytoma grade III the median survival was found to be superior by 5 years when randomized to neoadjuvant TMZ. This trial also confirmed the importance of $M G M T$ promoter methylation for the efficacy of TMZ.

The third study (paper III) investigated international practices for analyzing tumor $M G M T$ promoter methylation status. MGMT analysis can be conducted by various laboratory methods, which in some cases can provide opposing results regarding the MGMT methylation status of the patient's tumor. This can lead to incorrect treatment recommendations. To establish which methods and cut-offs that are regularly used to determine tumor MGMT status in the clinic, an international survey was provided to those working in the field. We also inquired about opinions regarding an international consensus on how MGMT should be tested. The 152 respondents reported several methodologies and different cut-off levels also for the same method. A majority of respondents warrant international guidelines. 
In conclusion, the results of the 2 randomized trials contribute to individualized treatment recommendations for patients affected by GBM or astrocytoma grade III. The results of the survey regarding analyses of MGMT clarify the current problematic situation. The request of the respondents regarding international guidelines might contribute to their future development, so that personalized treatment recommendations can be improved.

Keywords: high grade glioma, glioblastoma, astrocytoma grad III, radiotherapy, temozolomide, survival, MGMT status, survey 


\section{Populärvetenskaplig sammanfattning}

Gliom är den vanligaste typen av elakartad hjärntumör. I Sverige insjuknar ungefär 500 personer årligen. Tumörerna graderas från 1-4. Glioblastom, som är grad 4, är den mest aggressiva sorten. De flesta som insjuknar är över 60 år gamla. Standard behandling för glioblastom är kirurgi följt av strålning och cytostatika behandling med temozolomid (TMZ). Äldre har sämre prognos och har svårare att tåla omfattande behandling.

I en internationell studie har vi jämfört effekten av strålbehandling under 6 veckor, som är standard för yngre, mot komprimerad strålning under 2 veckor, eller mot behandling med TMZ. Sammanlagt ingick 342 patienter från Europa i undersökningen. De var alla över 60 år gamla och hade nyligen diagnosticerats med glioblastom. Resultatet från studien visade att överlevnaden var bättre för de som behandlades med TMZ jämfört mot 6 veckors strålning. Om man analyserade de som var över 70 år separat var både TMZ och komprimerad strålning bättre än 6 veckors strålbehandling. Livskvalitetsundersökning talade också för att TMZ är den bästa behandlingen. Vid analys av tumörvävnaden kunde man visa att markören MGMT var av betydelse för effekten av TMZ. Om MGMT genen var aktiv (ometylerad) så reparerades skadorna på DNA som orsakades av TMZ och tumörcellerna överlevde. Om $M G M T$ var inaktivt (metylerad), så dog tumörcellerna och patienterna överlevde längre.

I en andra studie undersökte vi om det kunde vara en fördel att ge TMZ mellan operationen för tumören och start av strålbehandlingen. Det är ofta väntetider innan strålningen kan komma igång och en del patienter hinner försämras under väntetiden. I denna studie ingick patienter med glioblastom ( grad 4) eller sk astrocytom grad 3. Alla patienter var 60 år eller yngre. Patienterna fick antingen strålbehandling på sedvanligt sätt under 6 veckor eller 2-3 cykler med TMZ följt av strålningen. En cykel TMZ gavs under 5 dagar efterföljt av uppehåll. Ny cykel startade efter 4 veckor. I denna undersökning ingick 144 patienter från Norden. Resultatet visade att överlevnaden var 5 år längre (95 månader istället för 35) för de som hade astrocytom grad 3 om de fick 2-3 cykler TMZ innan strålningen. Däremot var det inte någon vinst med att ge 2-3 kurer TMZ före start av strålbehandlingen för de som hade glioblastom. Även här visade sej MGMT status (metylerat eller ometylerat) vara av betydelse för effekten av TMZ.

MGMT är viktig för effekten av TMZ, som dessa 2 studier har visat. Men MGMT kan undersökas med olika metoder, som kommer att välja ut något olika patienter som känsliga för TMZ behandling. Detta kan vara ett problem när resultatet av MGMT analysen styr vilken behandling som ska ges. I en internationell enkät tillfrågades fr a patologer som specialiserat sig på hjärntumörer vilken metod de använder för MGMT analys och hur de utifrån sina resultat beräknar om $M G M T$ är metylerat eller inte. De tillfrågades också om de tycker att det skulle behövas internationella riktlinjer för hur man ska analysera MGMT. Sammanlagt svarade 152 personer på enkäten. Det visar sig att man använder ett flertal olika metoder, men också att för samma metod så beräknas MGMT på olika sätt. Majoriteten som svarade på enkäten önskar att det införs internationella riktlinjer kring hur MGMT ska analyseras och beräknas. 



\section{Table of contents}

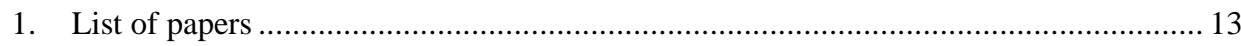

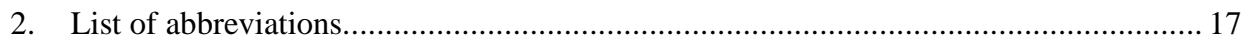

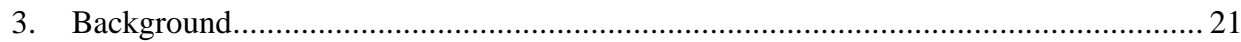

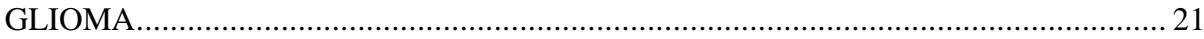

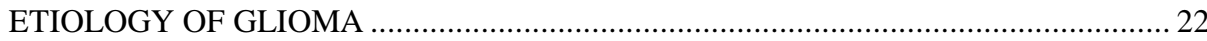

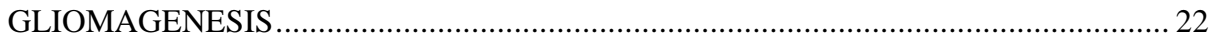

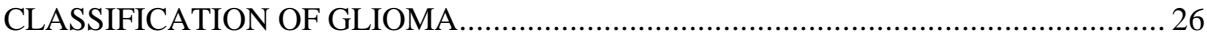

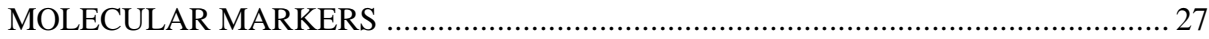

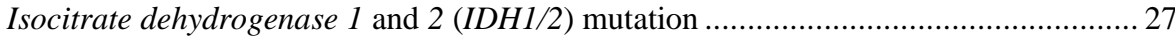

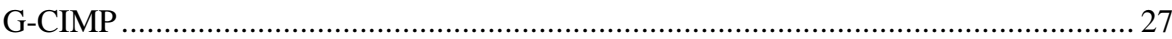

Codeletion of chromosomal arms 1p and 19q (Codel 1p/19q)................................ 27

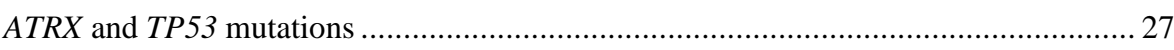

Telomerase Reverse Transcriptase (TERT) ……................................................. 27

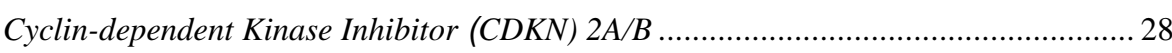

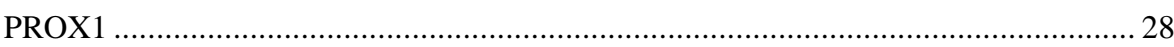

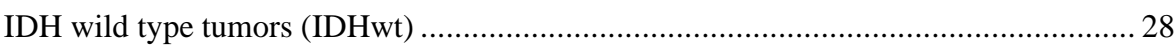

$O^{6}$-methylguanine DNA methyltransferase $(M G M T)$.............................................. 28

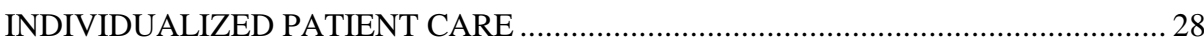

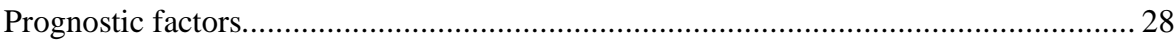

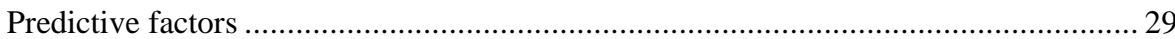

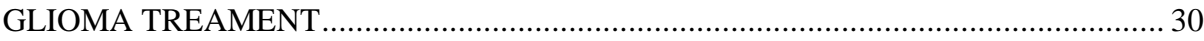

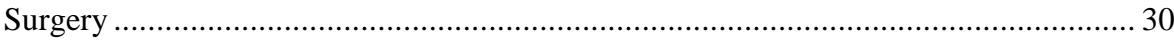

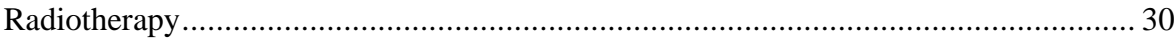

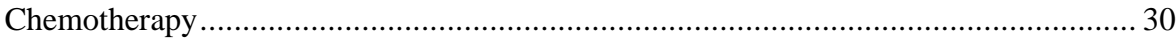

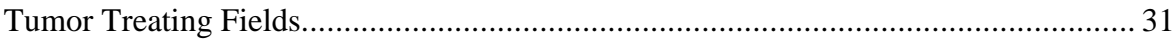

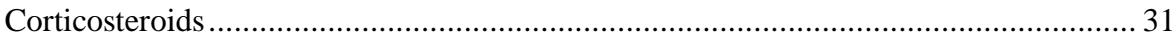

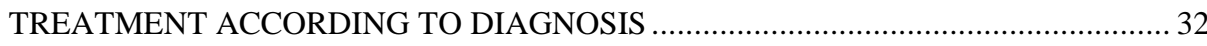

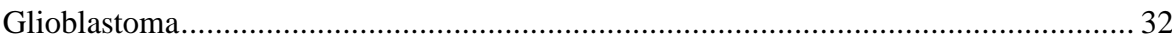

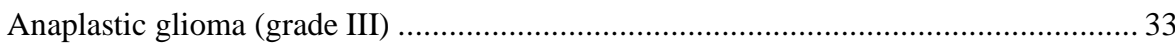

Low-grade glioma (grade II): diffuse astrocytoma and oligodendroglioma ................... 34

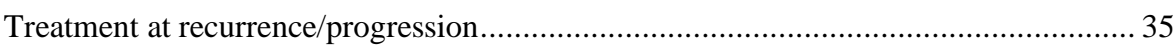

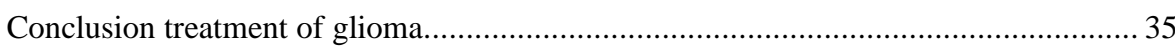

PATIENT CARE BEYOND TUMOR SPECIFIC TREAMENT ...................................... 35 


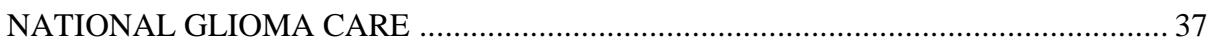

The Swedish National Brain Tumor Group (SNBTG) ................................................. 37

The Swedish National Quality Registry for Primary Brain Tumors (SNQR)................. 37

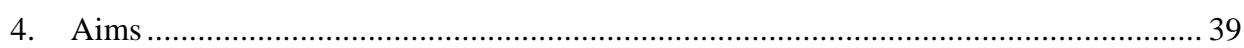

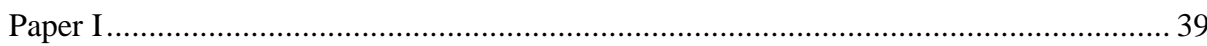

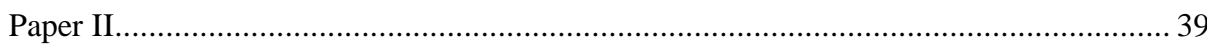

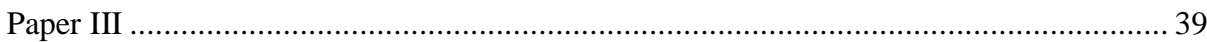

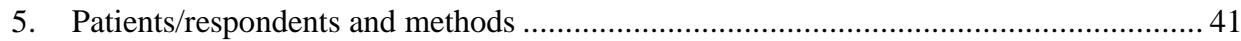

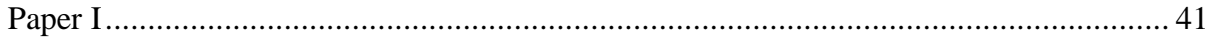

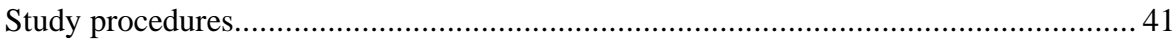

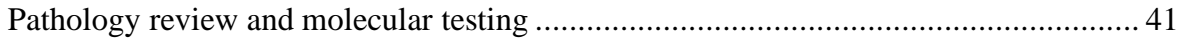

Primary and Secondary endpoints ........................................................................ 42

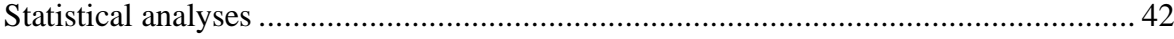

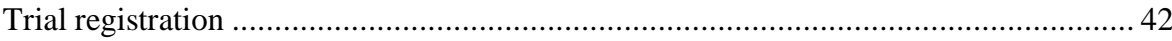

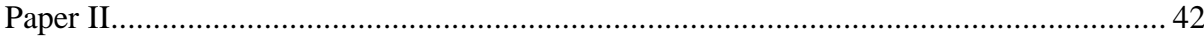

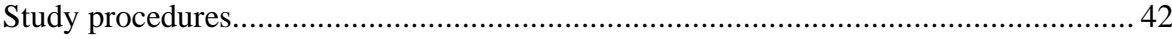

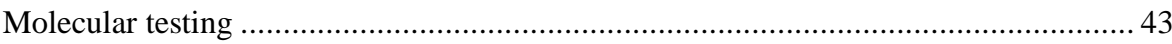

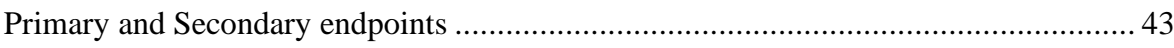

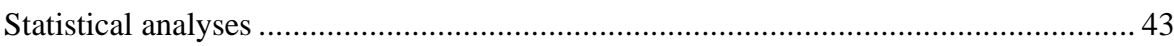

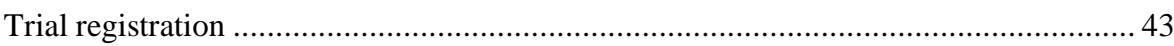

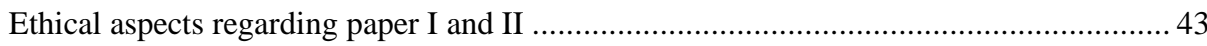

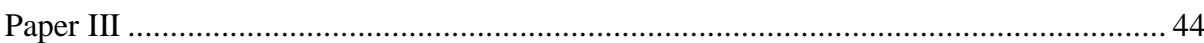

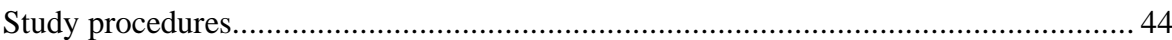

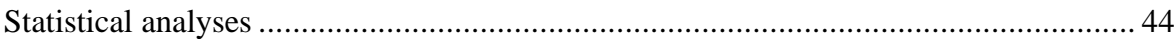

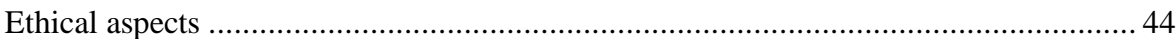

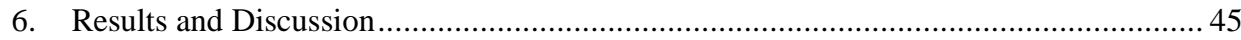

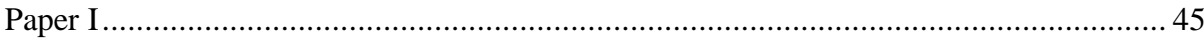

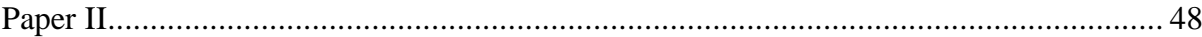

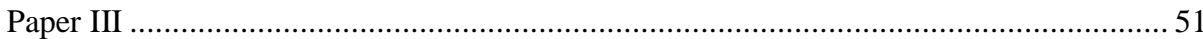

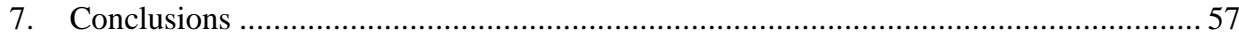

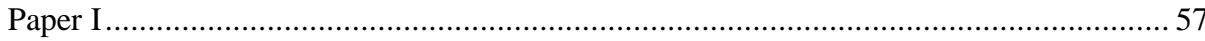

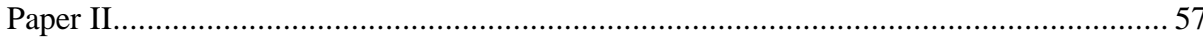

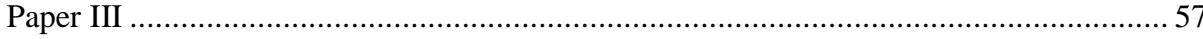

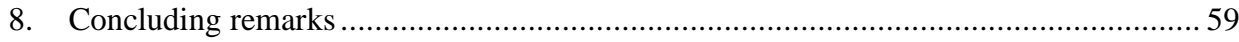

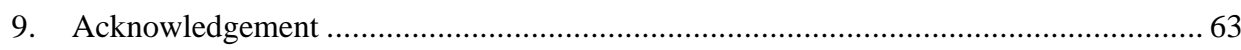


10. References

11. Appendix 



\section{List of papers}

This thesis is based on the following original papers, which are referred to in the text by their Roman numerals.

\section{Paper I.}

Malmström A, Grønberg BH, Marosi C, Stupp R, Frappaz D, Schultz H, Abacioglu U, Tavelin B, Lhermitte B, Hegi ME, Rosell J, Henriksson R;

Nordic Clinical Brain Tumour Study Group (NCBTSG).

Temozolomide versus standard 6-week radiotherapy versus hypofractionated radiotherapy in patients older than 60 years with glioblastoma: the Nordic randomised, phase 3 trial. Lancet Oncol. 2012:13(9):916-26.

\section{Paper II.}

Malmström A, Poulsen HS, Grønberg BH, Stragliotto G, Hansen S, Asklund T, Holmlund B, Łysiak M, Dowsett J, Kristensen BW, Söderkvist P, Rosell J, Henriksson R;

Nordic Clinical Brain Tumor Study Group (NCBTSG).

Postoperative neoadjuvant temozolomide before radiotherapy versus standard radiotherapy in patients 60 years or younger with anaplastic astrocytoma or glioblastoma: a randomized trial. Acta Oncol. Dec 2017;56(12):1776-1785.

Paper III.

Malmström A, Łysiak M, Kristensen BW, Hovey E, Henriksson R, Söderkvist P Do we really know who has an $M G M T$ methylated glioma?

Results of an international survey regarding use of MGMT analyses for glioma Published online 24 Sept 2019 in Neuro-Oncology Practice, doi.org/10.1093/nop/npz039 
Publications in neuro-oncology outside this thesis:

1. Coomans M, Dirven L, K Aaronson N, Baumert BG, van den Bent M, Bottomley A, Brandes AA, Chinot O, Coens C, Gorlia T, Herrlinger U, Keime-Guibert F, Malmström A, Martinelli F, Stupp R, Talacchi A, Weller M, Wick W, Reijneveld JC, Taphoorn MJB; EORTC Quality of Life Group and the EORTC Brain Tumor Group. The added value of health-related quality of life as a prognostic indicator of overall survival and progression-free survival in glioma patients: a meta-analysis based on individual patient data from randomised controlled trials. Eur J Cancer. 2019 Jul;116:190-198.

2. Dahlrot RH, Dowsett J, Fosmark S, Malmström A, Henriksson R, Boldt H, de Stricker K, Poulsen HS, Łysiak M, Söderkvist P, Rosell J, Hansen S, Kristensen BW. Prognostic value of O-6-methylguanine-DNA methyltransferase (MGMT) protein expression in glioblastoma excluding nontumour cells from the analysis. Neuropathol Appl Neurobiol. Feb 2018;44(2):172-184.

3. Roodakker KR, Elsir T, Edqvist PD, Hägerstrand D, Carlson J, Lysiak M, Henriksson R, Pontén F, Rosell J, Söderkvist P, Stupp R, Tchougounova E, Nistér M, Malmström A**, and Smits A**. PROX1 is a novel pathway-specific prognostic biomarker for high-grade astrocytomas; results from independent glioblastoma cohorts stratified by age and IDH mutation status. Oncotarget. Nov 08 2016;7(45):72431-72442.

**These authors share senior responsibility

4. Mason M, Laperriere N, Wick W, Reardon DA, Malmström A, Hovey E, Weller M, Perry JR. Glioblastoma in the elderly: making sense of the evidence. Neuro-Oncology Practice, Volume 3, Issue 2, 1 June 2016, Pages 77-86.

5. van Thuijl HF, Mazor T, Johnson BE, Fouse SD, Aihara K, Hong C, Malmström A, Hallbeck M, Heimans JJ, Kloezeman JJ, Stenmark-Askmalm M, Lamfers ML, Saito N, Aburatani H, Mukasa A, Berger MS, Söderkvist P, Taylor BS, Molinaro AM, Wesseling P, Reijneveld JC, Chang SM, Ylstra B, Costello JF. Evolution of DNA repair defects during malignant progression of low-grade gliomas after temozolomide treatment. Acta neuropathologica. Apr 2015;129(4):597-607.

6. Mosrati MA, Malmström A, Lysiak M, Krysztofiak A, Hallbeck M, Milos P, Hallbeck AL, Bratthäll C, Strandéus M, Stenmark-Askmalm M, Söderkvist P. TERT promoter mutations and polymorphisms as prognostic factors in primary glioblastoma. Oncotarget. Jun 30 2015;6(18):16663-16673.

7. Asklund T, Malmström A, Bergqvist M, Bjor O, Henriksson R. Brain tumors in Sweden: data from a population-based registry 1999-2012. Acta Oncol. Mar 2015;54(3):377-384. 
8. Asklund T, Malmström A, Bjor O, Blomquist E, Henriksson R. Considerable improvement in survival for patients aged 60-84 years with high grade malignant gliomas -- data from the Swedish Brain Tumour Population-based Registry. Acta Oncol. Jun 2013;52(5):1041-1043.

9. Asklund T, Bjor O, Malmström A, Blomquist E, Henriksson R. [Survival in malignant gliomas has increased the last decade. Analysis of quality data]. Lakartidningen. Apr 25-May 8 2012;109(17-18):875-878.

10. Malmström A, Stupp R, Hegi M, Rosell J, Henriksson R. Treatment options in elderly patients with glioblastoma - Authors' reply. The lancet oncology. Nov 2012;13(11):e461-462.

11. Bergenheim T, Malmström A, Bolander H, Michanek A, Stragliotto G, Damber L, Björ O, Henriksson R. [Registration on regional basis of patients with primary brain tumors. Regional differences disclosed]. Lakartidningen. Jan 31-Feb 6 2007;104(5):332-338, 340-331.

12. Henriksson R, Malmström A, Bergström P, Bergh G, Trojanowski T, Andreasson L, Blomquist E, Jonsborg S, Edekling T, Salander P, Brännström T, Bergenheim AT. High-grade astrocytoma treated concomitantly with estramustine and radiotherapy. Journal of neuro-oncology. Jul 2006;78(3):321-326.

13. Henriksson R, Berg G, Andreasson L, Bergenheim T, Blomqvist E, Edekling T, Malmström A, Malmström P, Skagerberg G. [SBU is wrong on radiotherapy of brain tumors. Early postoperative therapy prolongs the symptom-free period]. Lakartidningen. Sep 24 1997;94(39):3423-3424.

14. M Coomans, L Dirven, N Aaronson, B Baumert, M vd Bent, A Bottomley, A Brandes, O Chinot, C Coens, T Gorlia, U Herrlinger, F Keime-Guibert, A Malmström, F Martinelli, R Stupp, A Talacchi, M Weller, W Wick, J Reijneveld and M Taphoorn, on behalf of the EORTC Quality of Life Group. Symptom clusters in newly diagnosed glioma patients: which symptom clusters are independently associated with functioning and global health status?

Neuro-Oncology, noz118, https://doi.org/10.1093/neuonc/noz118 Published online 05 June 2019

15. A Malmström, M Łysiak, L Åkesson, I Jakobsen, M Mudaisi, P Milos, M Hallbeck, V Fomichov Casaballe, H Broholm, K Grunnet, H Skovgaard Poulsen, C Bratthäll, M Strandeus, A Papagiannopoulou, M Stenmark-Askmalm, H Green, P Söderkvist. ABCB1 single nucleotide variants and survival in patients with glioblastoma treated with radiotherapy concomitant with temozolomide. The Pharmacogenomics Journal DOI: 10.1038/s41397-019-0107-z Published online 17 Oct 2019 


\section{Manuscript in press}

Assessment of genetic and non-genetic risk factors for venous thromboembolism in glioblastoma - the predictive significance of B blood group

M Heenkenda, A Malmström, M Lysiak, M Mudaisi, C Bratthäll, P Milos, M

Strandeus, L Åkesson, P Söderkvist, S Uppugunduri, A Osman

In press in Thrombosis Research 


\section{List of abbreviations}

$19 q$ - Long arm of chromosome 19

$1 \mathrm{p}$ - Short arm of chromosome 1

2HG - 2-Hydroxyglutarate

$\alpha \mathrm{KG}-\alpha$-Ketoglutarate

AA - Anaplastic Astrocytoma (grade III)

ABCB1 - ATP-Binding Cassette sub-family B member 1

ARF - ADP Ribosylation Factor

ASCO - American Society of Clinical Oncology

ATRX - Alpha Thalassemia/Mental Retardation Syndrome X-Linked

BCNU - Carmustine

BN20 - Brain Cancer Module of the EORTC Quality of Life Questionnaire

CATNON - Concurrent and/or adjuvant TMZ for $1 \mathrm{p} / 19 \mathrm{q}$ non-codeleted tumors trial

CCNU - Lomustine

CDK4 - Cyclin-dependent Kinase 4

CDKN2A/B - Cyclin-dependent Kinase Inhibitor 2A/B

$\mathrm{CI}$ - Confidence Interval

CIC - Capicua Transcriptional Repressor

CNS - Central Nervous System

CODEL - 1p/19q codeleted glioma trial

CpG - Cytidine-phosphate-Guanosine

DKFZ - Deutsches Krebsforschungszentrum, German Cancer Research Center

DMR1 and 2 - Differentially Methylated Region 1 and 2

DNA - Deoxyribonucleic Acid

EANO - European Association of Neuro-Oncology

EGFR - Epidermal Growth Factor Receptor

EORTC - European Organisation for Research and Treatment of Cancer

FUBP1 - Far Upstream Element Binding Protein 1

GBM - Glioblastoma (grade IV)

G-CIMP - Glioma CpG Island Methylator Phenotype

GWAS - Genome Wide Association Study

Gy - Gray, radiation dose

HR - Hazard Ratio

HRT - Hypofractionated Radiotherapy

ICV - Intracranial Volume

IDH 1 - Isocitrate dehydrogenase 1

IDH 2 - Isocitrate dehydrogenase 2

IDHmut - IDH mutated

IDHwt $-I D H$ wild type

IHC - Immunohistochemistry

ISRCTN - Primary Clinical Trial Registry (International Standard Randomised Controlled

Trial Number) 
LGG - Low Grade Glioma (grade II)

MDM2 - Mouse Double Minute 2 Homolog

MGMT - $\mathrm{O}^{6}$-methylguanine DNA methyltransferase

mMGMT- methylated $M G M T$ promoter

MRI - Magnetic Resonance Imaging

mRNA - Messenger Ribonucleic Acid

Ms-MLPA -Methylation Specific Multiplex Ligation-Dependent Probe Amplification

MsPCR - Methylation Specific Polymerase Chain Reaction

$\mathrm{N}$ - number of patients

NCBTSG - Nordic Clinical Brain Tumor Study Group

NeoTMZ - Neoadjuvant Temozolomide

NF1 - Neurofibromatosis type 1

NOA - Neuro-Oncology Working Group of the German Cancer Society

Non-mMGMT- unmethylated MGMT promoter

OR - Overall Risk

OS - Overall Survival

p53 - Protein 53

PCV - Procarbazine, CCNU (lomustine) and Vincristine

PD-1 - Programed Death -1

PDGFRA - Platelet Derived Growth Factor Receptor A

PD-L1 - Programed Death - Ligand 1

PD-L2 - Programed Death - Ligand 2

PFS - Progression Free Survival

PI3K - Phosphatidylinositol-3-OH Kinase

PREM - Patient Reported Experience Measures

PROM - Patient Reported Outcome Measures

PROX1 - Prospero Homeobox Protein 1

PS - Performance Status

PTEN - Phosphatase and Tensin Homolog

QLQ-30 - EORTC Quality of Life Questionnaire

$\mathrm{RB}$ - Retinoblastoma

RB1 - RB Transcriptional Corepressor 1

RT - Radiotherapy

RTK - Receptor Tyrosine Kinase

RTOG - Radiation Therapy Oncology Group

SNBTG - Swedish National Brain Tumor Group

SNQR - Swedish National Quality Registry for Primary Brain Tumors

SNV - Single Nucleotide Variants

SPECTA - Screening Patients for Efficient Clinical Trials Access

SRT - Standard Radiotherapy

TCGA - The Cancer Genome Atlas

TERT - Telomerase Reverse Transcriptase

TET2 - Ten-Eleven Translocation Methylcytosine Dioxygenase 2

TMZ - Temozolomide 
TP53 - Tumor Protein p53 gene

TSS - Transcription Start Site

TTF - Tumor Treating Fields

VEGF - Vascular Endothelial Growth Factor

Vs - versus

WHO - World Health Organization 


\section{Background \\ GLIOMA}

Glioma is the most frequent malignant primary brain tumor and accounts for approximately $50 \%$ of all primary intracranial tumors, the other half mainly consisting of meningioma ${ }^{1}$. Gliomas belong to the most malignant tumors. They comprise approximately $1 \%$ of all cancers diagnosed in Sweden with over 500 persons being diagnosed with glioma annually ${ }^{1,2}$. It is a disease that can cause a variety of neurological symptoms, mainly reflecting the function of the site of the tumor in the brain. It can lead to motor dysfunction as well as cognitive symptoms and personality change. Apart from affecting the patient it often also largely affects the family ${ }^{3}$. To date, cure is extremely rare and the intent of all treatment is to diminish symptoms, delay disease progression, and to provide maximal prolongation of survival with as good quality of life as possible.

Gliomas are subdivided according to malignancy grade and morphological features. Since 2016 also molecular markers have been included into the WHO classification, helping to further separate the tumors according to biological properties ${ }^{4}$.

Glioblastoma (GBM), the most frequent and most aggressive glioma, has an expected median survival of 15 months with standard of care, which includes both radiotherapy (RT) and chemotherapy with the alkylating agent temozolomide (TMZ) ${ }^{5}$. In Sweden, median age at diagnosis is 64 years $^{\mathrm{a}}$ for those with diagnostic surgery ${ }^{1}$. There is a male predominance with the ratio male to female being $1.4: 1^{\mathrm{b}}$. Many patients are not fit for oncological treatment due to comorbidities, decreased performance status and cognitive deficits. These patients will be candidates for palliative care alone ${ }^{6}$.

Low grade glioma (LGG) more frequently affect younger patients, with median age at diagnosis being 44 years $^{\mathrm{a} 1}$. They have a better prognosis and also response to treatment, but the disease is still fatal. Even radically excised tumors will eventually recur and over time often develop more aggressive features. Median survival is estimated to 7 years ${ }^{7}$.

Due to the dismal prognosis for glioma there is great need for improving the outcome of those affected by this disease, both by prolonging survival, and by improving quality of life (QoL) and psychosocial care. By adopting personalized medicine, toxicity can be minimized by selecting patients for the correct therapy and by refraining from providing ineffective treatment.

The aim of the studies in this thesis is to contribute to the improvement of individualized care of glioma patients, mainly focusing on therapeutic interventions but also by elucidating the challenges in assessing the crucial treatment predictive factor MGMT in the clinic.

\footnotetext{
${ }^{a}$ Median age compiled from data from 1999-2018 in the Swedish National Quality Registry according to the previous, nonmolecular classification.

${ }^{\text {b} R a t i o ~ b e t w e e n ~ m e n ~ a n d ~ w o m e n ~ f o r ~ h i g h ~ g r a d e ~ g l i o m a ~ c o m p i l e d ~ f r o m ~ d a t a ~ f r o m ~ 1999-2016 ~ i n ~ t h e ~ S w e d i s h ~ N a t i o n a l ~ Q u a l i t y ~}$ Registry according to the previous, non-molecular classification.
} 


\section{ETIOLOGY OF GLIOMA}

Little is known about the etiology of glioma. An increased risk has been noted for patients with neurofibromatosis type I, Turcot syndrome and Li Fraumeni Syndrome ${ }^{8}$. Familial gliomas do occur, but are uncommon ${ }^{9-11}$. Apart from increasing age, male gender, and Caucasian ethnicity, also an association between exposure to ionizing radiation and risk of glioma has been determined, while a decreased risk in patients with asthma/atopic disease has been suggested ${ }^{11}$. Genome-Wide Association Studies (GWAS) have identified 25 Single Nucleotide Variants (SNV) correlating to increased risk of glioma ${ }^{11}$. In a case-control study, for some of these SNVs a relationship to gliomas with specific molecular profiles could be established $^{12}$.

An interesting study analyzed intracranial volume (ICV), as a substitute for brain size, and its association to risk of developing a glioma. It was found that an increase in ICV of $100 \mathrm{ml}$ led to an increased risk of developing glioma, with an odds ratio of 1.69 (95\% CI: 1.44-1.98; $\mathrm{p}<0.001)$. After adjusting for ICV, the statistical analysis resulted in males having a decreased risk of glioma instead of females (OR 0.56, 95\% CI: $0.33-0.93)^{13}$. The relationship to brain size is believed to be due to a larger number of neuroglial stem cell divisions in a larger brain, and that this constitutes a higher risk for tumor development.

\section{GLIOMAGENESIS}

In the normal cell there is a balance between proliferation, differentiation and suppression of growth according to the needs of the tissue. If this balance is upset, a tumor may arise. Tumors are the result of a multi-step process, where an increasing number of mutations accumulate over time ${ }^{14}$. Loss of growth inhibition can be caused by mutations of genes regulating proliferation, called oncogenes, where one hit can be enough to evade growth control. The genes coding for factors counteracting growth signaling, called tumor suppressor genes, commonly need mutations or losses on both alleles for loss of control of proliferation.

During the development of a cancer several additional capabilities or hallmarks are acquired, including resistance to apoptosis, stimulation of angiogenesis, replicative immortality, reprogrammed cell metabolism and inactivation of the immune defense. The capability to metastasize is common in most cancers, but for glioma is limited to within the brain. Genetic instability in tumor cells and inflammatory processes, often involving normal cells, influence the cancer hallmarks and add another layer of complex cellular interactions ${ }^{15}$.

Apart from mutations that can affect critical signaling pathways, also epigenetic changes can contribute to the development of tumors. Methylation of the promoter region can lead to silencing of transcription of the affected gen, which could be crucial for normal function ${ }^{14}$. The different hallmarks of carcinogenesis also contribute to the development of brain tumors.

Gliomas are believed to arise from neural stem cells ${ }^{16}$. Two major paths of gliomagenesis have been identified, where one harbors mutations in isocitrate dehydrogenase (IDH). The molecular events leading to a glioma are different for IDH mutated (IDHmut) versus IDH wildtype (IDHwt) tumors. While the steps resulting in IDHmut tumors are relatively well understood, for IDHwt glioma less is known about the order of the molecular changes leading to a glioblastoma. 
Mutations of $I D H 1$ and $I D H 2$ (on chromosome $2 \mathrm{q}$ and $15 \mathrm{q}$ respectively) are believed to be an early event ${ }^{17}$ and typically target Arginine 132 in $I D H 1$ that is substituted by Histidine in $80-90 \%$ of IDHmut tumors (R132H). In the corresponding position, Arginine 172 in IDH2 can be replaced by Lysine in 2-3\% of IDHmut cases (R172K). These mutations are mutually exclusive. Other uncommon mutations do occur and can result in other amino acid changes. The normal function of the enzymes IDH1 and 2 is to catalyze the conversion of isocitrate to $\alpha$-ketoglutarate $(\alpha \mathrm{KG})$ in the tricyclic acid cycle. While IDH1 is localized in the cytosol and perioxisomes, IDH2 is located in the inner mitochondrial membrane. The mutated IDHI/2 gene product obtains a neomorphic enzymatic activity, which will lead to the formation of an oncometabolite, D-2-hydroxyglutarate (2HG) and a corresponding reduction of $\alpha \mathrm{KG}$. $2 \mathrm{HG}$ interferes with several cellular processes, e.g. it inhibits histone demethylases and the activity of TET enzymes, which normally catalyze the first step in the DNA demethylation process.

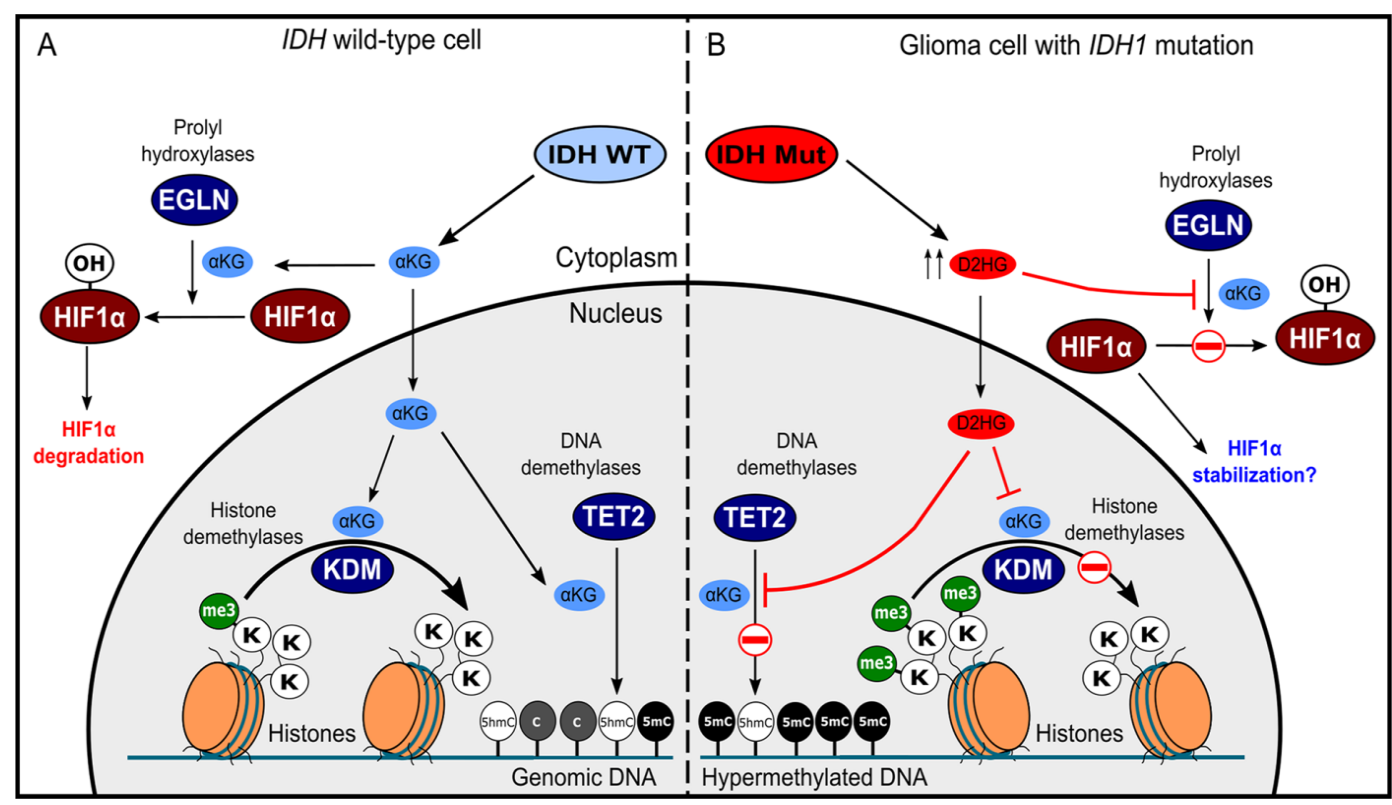

Figure 1. Cellular effects of elevated D2HG levels in glioma cells. 2HG can accumulate in glioma cells to levels $>100$-fold compared with normal tissue. $\alpha \mathrm{KG}$ functions as a cofactor for several cellular dioxygenases, including histone lysine demethylases, TET cytosine hydroxylases, and HIF prolyl hydroxylases. Excessive D2HG accumulation disrupts the normal function of $\alpha \mathrm{KG}$-dependent enzymes.

Reprinted with permission from reference ${ }^{17}$.

This will influence cellular epigenetics and genome-wide DNA methylation. As a consequence, IDH mutated glioma are strongly associated with the glioma-CpG island methylator phenotype (G-CIMP) ${ }^{18}$. One way of IDH mutations to contribute to tumorigenesis is believed to be via the inhibition of the TET enzymes, mainly TET2, leading to dysregulation of DNA demethylation ${ }^{17}$. $2 \mathrm{HG}$ also inhibits normal differentiation, by inactivating methylations of important gene promoters (Figure 1). 
IDH mutant tumors will over time acquire additional molecular alterations that will define tumor lineage and relation to histology. Oligodendroglioma will have codeletions of the short arm of chromosome 1 and the long arm of chromosome 19 (codel 1p/19q), an event caused by an unbalanced translocation ${ }^{19,20}$. They will typically also have oncogenic mutations in the promoter of the telomerase gene (TERT) and mutations in CIC and/or FUBP1 (located on 19q and $1 \mathrm{p}$ respectively). IDH mutated astrocytic tumors lack the $1 \mathrm{p} / 19 \mathrm{q}$ codeletion, but often have TP53 mutation and inactivating mutations in ATRX (Alpha Thalassemia/Mental Retardation Syndrome X-Linked). Interestingly, mutations in ATRX and TERT both affect telomere function and are mutually exclusive ${ }^{21}$. LGG are known to often progress to higher grade (more aggressive) tumors, by acquiring additional molecular changes. Oligodendroglioma may progress to grade III tumor at the most (anaplastic oligodendroglioma), but astrocytoma can malignify into an anaplastic astrocytoma (grade III) or a secondary GBM (astrocytoma grade IV). While often histologically indistinguishable from a primary GBM, molecular alterations, clinical factors and prognosis differ (Table 1).

\begin{tabular}{|l|l|l|}
\hline & $\begin{array}{l}\text { IDH-wildtype } \\
\text { glioblastoma }\end{array}$ & $\begin{array}{l}\text { IDH-mutant } \\
\text { glioblastoma }\end{array}$ \\
\hline Synonym & $\begin{array}{l}\text { Primary glioblastoma, } \\
\text { IDHwt }\end{array}$ & $\begin{array}{l}\text { Secondary } \\
\text { glioblastoma, } \\
\text { IDHmut }\end{array}$ \\
\hline Precursor lesion & $\begin{array}{l}\text { Not identifiable; } \\
\text { Develops de novo }\end{array}$ & $\begin{array}{l}\text { Diffuse astrocytoma } \\
\text { Anaplastic astrocytoma }\end{array}$ \\
\hline Proportion of glioblastomas & $\approx 90 \%$ & $\approx 10 \%$ \\
\hline Median age at diagnosis & $\approx 62$ years & $\approx 44$ years \\
\hline Male-to-female ratio & $1.42: 1$ & $1.05: 1$ \\
\hline Mean length of clinical history & 4 months & 15 months \\
\hline $\begin{array}{l}\text { Median overall survival } \\
\text { Surgery+radiotherapy } \\
\text { Surgery+radiotherapy+chemotherapy }\end{array}$ & 15 months & 15 months \\
\hline Location & Supratentorial & 31 months \\
\hline Necrosis & Extensive & Preferentially frontal \\
\hline$T E R T$ promoter mutations & $72 \%$ & Limited \\
\hline TP53 mutations & $27 \%$ & $26 \%$ \\
\hline$A T R X$ mutations & Exceptional & $81 \%$ \\
\hline$E G F R$ amplification & $35 \%$ & $71 \%$ \\
\hline PTEN mutations & $24 \%$ & Exceptional \\
\hline
\end{tabular}

Table 1. Key characteristics of IDH-wildtype and IDH-mutant glioblastoma Adapted from ref ${ }^{4}$ with permission from the WHO

IDH wildtype GBM represent between $90-95 \%$ of all GBM. The different steps in GBM tumorigenesis are not so well known, therefore description of these tumors mainly define the incidence of molecular changes, where the reported proportion of genetic alterations will vary slightly between different published cohorts. The tumors arise de novo, without progression from a tumor with lower malignancy grade, and often harbor genetic changes in EGFR, 
PTEN, PDGFRA, NF1, CDKN2A/B and TERT ${ }^{22}$. Gains of chromosome 7 and loss of chromosome 10 are common. Molecular alterations mainly affect three signaling pathways: receptor tyrosine kinase (RTK), retinoblastoma (RB1), and p53. Alterations affecting the RTK family are EGFR amplifications (30-57\%) where approximately half will have a truncated and constitutively activated receptor (EGFRvIII variant) and PTEN deletions or mutations in $24-80 \%$ of cases. Other commonly affected members of the RTK pathway are PDGFRA (10-18\%), phosphatidylinositol-3-OH kinase (PI3K) (15-25\%) and NF1 (10-15\%). Alterations in the RB1 pathway include mutations and deletions of $C D K N 2 A / p 16(52 \%)$, amplifications of $C D K 4$ (14-18\%) and mutations/deletions of $R B 1$ (7-11\%). In the p53 signaling pathway the most frequent alterations affect mutations and deletions of CDKN2B/ARF (49\%), mutations in TP53 (28-35\%) and MDM2 amplification (7-14\%) ${ }^{4,22,23}$ (Figure 2.). The molecular alterations will generally cause activation of oncogenes and /or inactivation of tumor suppressor genes.

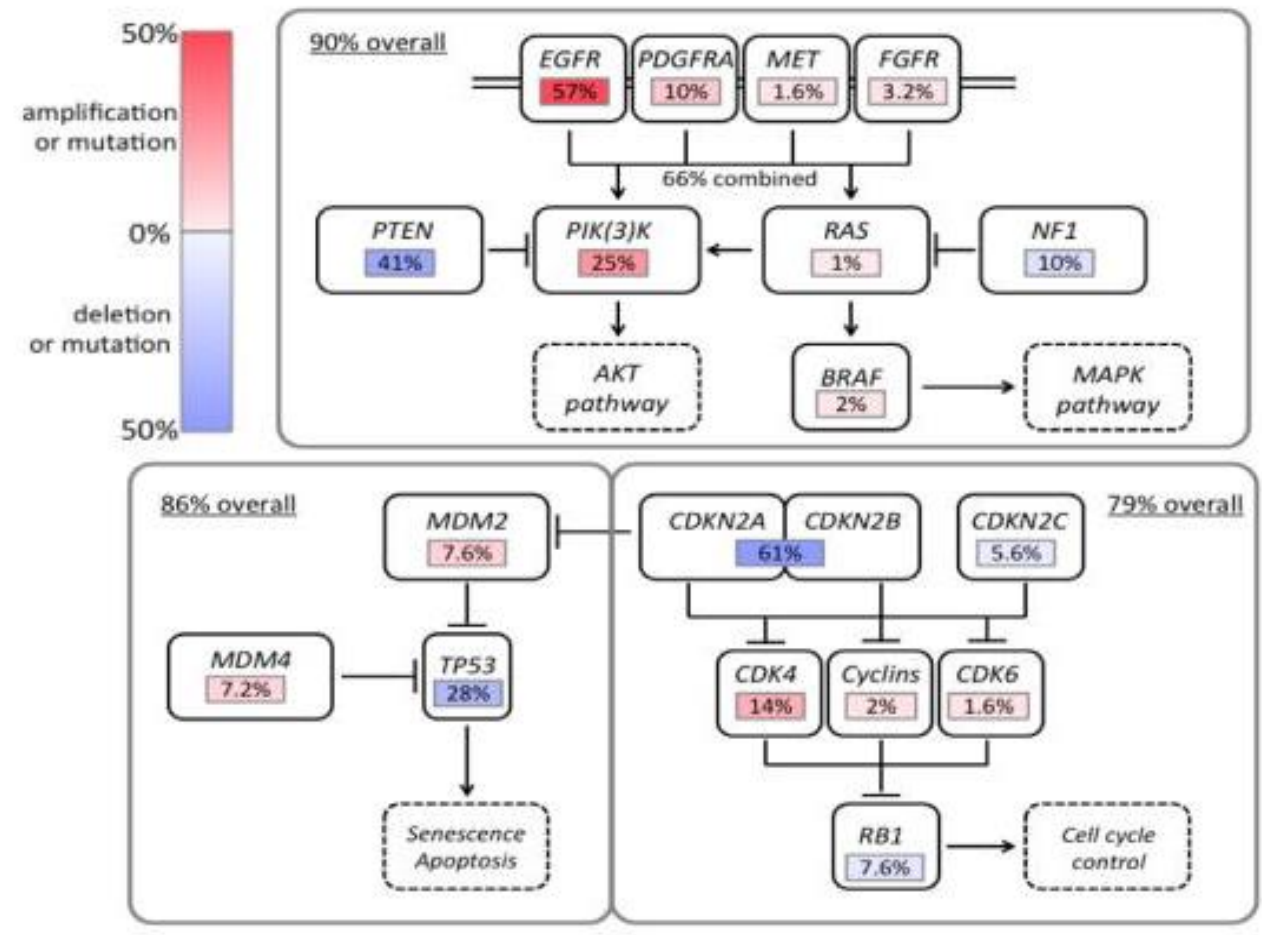

Figure 2. Overall alteration rate for PI3K/MAPK (RTK), p53 and Rb regulatory pathways in glioblastoma. Reprinted with permission from reference ${ }^{23}$.

In a study, multiple spatially separate samples from the same GBM were analyzed for molecular alterations. Copy number aberrations of EGFR and CDKN2A/Bp14ARF were identified as early events in tumorigenesis, while aberrations in PTEN and PDGFRA occurred later. Extensive intratumor heterogeneity was also noted ${ }^{24}$. 


\section{CLASSIFICATION OF GLIOMA}

During the last two decades there has been a vast development in our knowledge and understanding regarding molecular alterations in glioma. Gliomas have been classified according to pathological findings only until the new WHO classification of primary brain tumors included molecular markers (Figure 3.). The pathologist assesses morphological findings such as: tumor cellularity, nuclear atypia, necrosis, microvascular proliferation and mitosis, focusing on tumor phenotype $\mathrm{e}^{25}$. Reproducibility among different neuropathologists has been an issue when diagnosing glioma, due to subjectivity ${ }^{26,27}$. As different tumor types are expected to respond differently to therapies and harbor different prognoses, an accurate diagnosis is crucial for correct treatment decision making. The addition of molecular markers to the classical diagnostic criteria, reflecting the tumor genotype, lead to more congruent tumor groups with similar behavior, prognosis and response to treatment. With the new classification including molecular markers, the clinical differences in outcome between grade II and III tumors have been found to be smaller ${ }^{28}$. As a consequence, in the CODEL and IWOT trial (See Low grade glioma), in contrast to previous studies, both grade II and III tumors will be included ${ }^{29}$.

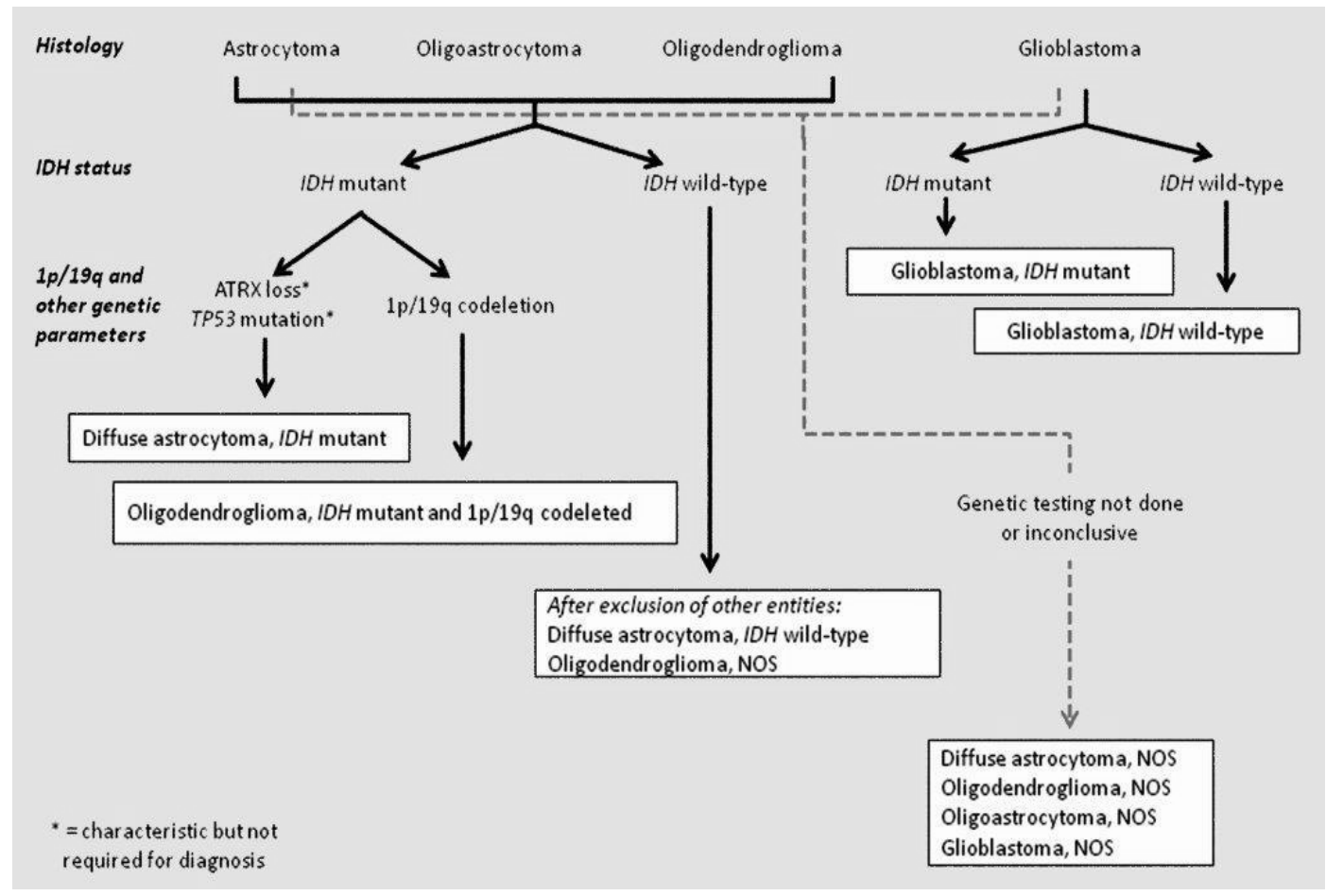

Figure 3. Algorithm for classification of diffuse gliomas, including histology and molecular genetics. A similar algorithm can be followed for anaplastic gliomas. Reprinted from reference ${ }^{4}$ with permission from the WHO.

The majority of gliomas are according to the updated WHO classification 2016 graded as grade IV (most malignant - Glioblastoma, GBM), grade III anaplastic astrocytoma and anaplastic oligodendroglioma and grade II diffuse astrocytoma and oligodendroglioma ${ }^{4}$. 


\section{MOLECULAR MARKERS}

\section{Isocitrate dehydrogenase 1 and 2 (IDH1/2) mutation}

During the beginning of the 2000's IDH mutations were shown to be of importance for the development of $\mathrm{LGG}^{17}$. It was discovered that IDHmut glioma could be further subdivided into those that carried the $1 \mathrm{p} 19 \mathrm{q}$ codeletion, called oligodendroglioma, having the best prognosis, and those lacking the codeletion, astrocytoma ${ }^{4}$.

\section{G-CIMP}

IDH mutations have been found to cause epigenetic changes leading to a glioma-Cytidinephosphate-Guanosine $(\mathrm{CpG})$ island methylator phenotype, called G-CIMP ${ }^{18}$. Tumor with $1 \mathrm{p} / 19 \mathrm{q}$ codeletion will carry a methylation pattern called G-CIMP-A (CIMP-codeleted) and non-codeleted tumor G-CIMP-B (CIMP non-codeleted) ${ }^{17}$. G-CIMP non-codeleted tumors can be further subdivided into G-CIMP-high or G-CIMP-low, the latter having poorer overall survival $^{18}$.

Methylation patterns of primary central nervous system (CNS) tumors have been shown to be relatively stable over time/disease progression and to be able to facilitate the classification of CNS tumors ${ }^{30,31}$. More about this under "Concluding remarks".

\section{Codeletion of chromosomal arms 1p and 19q (Codel 1p/19q)}

One of the first and most important molecular finding in gliomas was the codeletion of the chromosomal arms $1 \mathrm{p}$ and 19q, identified in oligodendroglioma. This is reported to be caused by a translocation ${ }^{32}$ and was shown already in the 90's to have clinical significance, as those with tumors carrying these deletions were shown to respond favorably to both RT and chemotherapy including alkylating agents, usually PCV treatment (Prokarbazin, CCNU and Vincristine) but also $\mathrm{TMZ}^{20,32,33}$. Patients with this molecular profile were as well identified as a subgroup of glioma with especially good prognosis ${ }^{34}$.

\section{$A T R X$ and TP53 mutations}

Loss of ATRX and/or TP53 mutations are often found in IDHmut astrocytic glioma (Figure 3.). While both loss of ATRX and TP53 mutations influence telomere function, TP53 mutations also inactivate the p53 pathway involved in cell cycle regulation. They are though not required for diagnosis.

\section{Telomerase Reverse Transcriptase (TERT)}

An additional molecular marker that has been of interest in the last decade is the TERT mutation, affecting the promoter area at C228T ( $-124 \mathrm{bp}$ from the transcription start site (TSS)) and C250T ( -146 bp) upstream the ATG start site. These are found in over $70 \%$ of $\mathrm{GBM}^{4}$ and constitute a negative prognostic factor, as we could confirm in a study by our group $^{35}$. We also identified two SNP's in TERT associated with an increased risk of developing GBM.

Interestingly, TERT promoter mutations at C228T and C250T can be found in IDHmut tumors as well and in oligodendroglioma they instead are a good prognosis factor ${ }^{36}$. 
Cyclin-dependent Kinase Inhibitor (CDKN) 2A/B

Homozygous deletions of $C D K N 2 A / B$, leading to cell cycle dysregulation, have been identified as a negative prognostic factor in IDHmut and TP53 mutated astrocytic glioma ${ }^{28,37}$.

\section{PROX1}

In a study of patients with mixed high-grade glioma we found that high levels of PROX1, examined by immunohistochemistry, in IDHmut non-codeleted tumors predicted poor survival. For IDHwt tumor no such effect was noted. The findings could be confirmed in $\mathrm{TCGA}^{38}$. These results need further confirmation from additional studies.

\section{IDH wild type tumors (IDHwt)}

Tumors lacking IDH mutations, IDHwt, are generally diagnosed as GBM, called primary GBM. IDHwt GBM usually have an aggressive course and median survival is expected to be around 15 months with standard of care, including radio-chemotherapy.

\section{$O^{6}$-methylguanine DNA methyltransferase (MGMT)}

Methylation of the promoter region of $O^{6}$-methylguanine DNA methyltransferase (MGMT) has in several randomized trials in GBM been shown to be of importance for response to treatment with the alkylating agent $\mathrm{TMZ}^{5,39-43}$. These include the Nordic trial for elderly patients (paper I). Also other alkylating agents are dependent on this methylation that causes silencing of the transcription of the MGMT gene $\mathrm{e}^{44}$. MGMT promoter methylation status is the most important predictive factor for alkylating agent treament ${ }^{39,40,42}$. For response to RT $M G M T$ status is not of importance, which therefore is the treatment of choice up to date for those with $M G M T$ unmethylated tumor ${ }^{40}$.

\section{INDIVIDUALIZED PATIENT CARE}

Over time there has been an increasing understanding of the need to individualize treatment recommendations for glioma patients, as for those with other malignancies. This should include both clinical prognostic factors and biological, mostly tumor related markers, and last but not least, patient's preferences.

\section{Prognostic factors}

The most important clinical prognostic factors for glioma patients are diagnosis, age, performance status and type of surgery ${ }^{1,40,45}$. Gender is usually referred to as being prognostic, as women are often reported to have better survival ${ }^{46}$. An analysis regarding gender differences in the Swedish National Quality Registry (SNQR), showed some differences for high grade glioma, but median survival was equal between men and women (315 versus (vs) 326 days, women vs men), even though for mean survival there was an advantage for women (742 vs 628 days, women vs men)(Poster P01.151 EANO (European Association of Neuro-Oncology) 2018) ${ }^{1}$. IDH mutations and especially $1 \mathrm{p} / 19 \mathrm{q}$ codeletions confer a better prognosis as compared to IDH wildtype tumors, as mentioned previously ${ }^{34}$. 


\section{Predictive factors}

$O^{6}$-methylguanin DNA methyltransferase (MGMT) and its testing

As mentioned above, for treatment with an alkylating agent, the methylation status of the promoter of the MGMT gene is determinant. Despite its importance for correct allocation of therapy, prognostication and informed treatment decision making with the patient and proxy, there is internationally no consensus on which method for analyzing MGMT or which cut-off for the method chosen that should be used to correctly discriminate patients expected to respond to TMZ treatment, from patients where TMZ will be ineffective. A number of publications have addressed this issue $\mathrm{e}^{47-50}$.

The CpG island of the promoter of MGMT has $97 \mathrm{CpG}$ sites where methylation can occur ${ }^{51}$. Not all patterns of methylation will lead to gene transcription silencing. The differentially methylated regions 1 and 2 (DMR 1 and 2) are located, DMR1 upstream and DMR 2 downstream, of the TSS. These $\mathrm{CpG}$ rich regions have been identified to be the most influential for transcriptional silencing of $M G M T$ according to several publications ${ }^{52-55}$.

Each cytosine in the $\mathrm{CpG}$ islands can be methylated. All CpGs will jointly affect transcription but the minimal number of methylated $\mathrm{CpGs}$ or the methylation pattern needed to render the tumor sensitive to TMZ is not known.

There are several methods to analyze MGMT methylation, many focusing on the CpG sites, others measure the gene product, the MGMT mRNA or the protein itself. The cut-off value (average methylation ratio over a number of $\mathrm{CpG}$ sites) for methylated versus unmethylated tumors can be calculated in different ways. As a consequence, in some cases, for the same patient the tumor can be determined as both methylated and unmethylated depending on the method and cut-off value used. This could in turn lead to incorrect treatment recommendations and have a negative effect on outcome and survival.

\section{IDH mutations}

IDH mutations and the G-CIMP caused by this is believed to render tumors more sensitive to chemotherapy as was found in the retrospective analyses of the anaplastic oligodendroglioma $\operatorname{trials}^{56,57}$.

\section{$1 p / 19 q$ codeletion}

The codeletion of chromosomal arms $1 \mathrm{p}$ and $19 \mathrm{q}$ select a group of glioma patients with especially favorable outcome to radiotherapy and PCV chemotherapy ${ }^{20,33,56}$. They also harbor IDH mutations.

\section{$A B C B 1$}

Not all patients with methylated $M G M T$ respond to $\mathrm{TMZ}$ treatment, therefore additional factors are believed to affect response to $\mathrm{TMZ}^{58}$. $\mathrm{ABCB} 1$ is an ATP dependent drug transporter, also called MDR-1 or p-glycoprotein, known to also transport TMZ. Its gene is known to harbor several SNVs that can alter its function ${ }^{59}$. We investigated four common SNVs of $A B C B 1$ to elucidate their influence on TMZ efficacy in a cohort of GBM patients treated with concomitant RT and TMZ. In our pilot cohort we found a correlation to inferior 
survival for those with the SNV 1199A/G, 11.5 months versus 18.2 months for the wild type SNV 1199G/G ( $\mathrm{p}=0.012$ ). This prompted us to expand our study and to include a confirmatory cohort. A clinically significant role of ABCB1 SNV 1199 G/A could though neither be confirmed in the expanded nor confirmatory cohort. This work is published online in the Pharmacogenomic Journal.

\section{GLIOMA TREAMENT}

Treatment modalities available for glioma are surgery, radiotherapy and chemotherapy. In the last couple of years, for GBM, tumor treating fields (TTF) have been added ${ }^{60}$. Standard of care for GBM and lower grade glioma differ regarding radiotherapy dose, timing and partially type of chemotherapy.

\section{Surgery}

For all patients surgery should be maximal safe resection. Evidence point to that resection is better than biopsy and that radical surgery will lead to the best prognosis ${ }^{45,61-63}$. Often considerations regarding neurological functioning and QoL can prohibit the complete removal of the tumor. Sometimes only biopsy, for histological and molecular diagnostic purposes, is possible, especially for patients with comorbidities or tumors in eloquent areas. The majority of patients with biopsy only are older than those undergoing resection ${ }^{1}$.

\section{Radiotherapy}

Radiotherapy (RT) is an essential part of glioma treatment. It is delivered to the tumor area, including the postoperative cavity, most often defined by MRI (gross tumor volume). To this a margin of $1-2.5 \mathrm{~cm}$ is added (clinical target volume). RT is a local treatment and the aim is to contribute to local tumor control. It can preserve function and has been shown to prolong survival ${ }^{8,64}$. Timing, fractionation and dosing depends on tumor type and prognostic factors, including age and performance status ${ }^{8}$.

RT can cause adverse events. This can occur directly, during ongoing therapy, so called acute toxicity. The risk is especially high if the tumor volume is large and/or the tumor is only biopsied. Patients can experience increase of neurological symptoms and/or headache shortly after the initiation of RT. This is usually counteracted by corticosteroid treatment. Subacute toxicity continues to affect the patients at the end of RT and over weeks up to a couple of months. Common symptoms are fatigue, concentration difficulties and mood changes. Late toxicity causes cognitive decline including memory problems, and develops years after RT. To avoid the risk of radionecrosis of normal brain tissue and organs at risk, such as the optic chiasma and hippocampus, they need to be accounted for when planning treatment ${ }^{65-67}$.

\section{Chemotherapy}

\section{Temozolomide}

Temozolomide (TMZ) is an oral alkylating agent with good penetration of the blood-brainbarrier. It is in several steps converted to the active compound that will add methyl groups to DNA in certain positions, including to $\mathrm{O}^{6}$-guanin residues. If this DNA damage is not repaired, it will in further steps lead to tumor cell death. $M G M T$ is a DNA repair gene and MGMT will remove the $\mathrm{CH}_{3}$ group at the $\mathrm{O}^{6}$ position of guanine and restitute the DNA. When this occurs the tumor cell will survive. Methylation of the promoter region can 
inactivate the transcription of the $M G M T$ gene and deplete the cell of $\mathrm{MGMT}^{51}$. This is a prerequisite for response to alkylating agent therapy.

Toxicity of TMZ is most often mild, common adverse events being nausea and myelosuppression, mostly affecting thrombocytes. Especially during the concomitant phase of treatment with TMZ and radiotherapy, lymphopenia together with corticosteroids can result in serious Pneumocystis jirovecii infections ${ }^{5,68}$. Fatal adverse events can occur, such as also other severe infections, bleeding complications due to thrombocytopenia, and myelodysplastic syndrome $e^{40,41}$.

\section{Carmustine and Lomustine}

Nitrosourea chemotherapy consists of several compounds, with lomustine (CCNU) administered orally and carmustine (BCNU) intravenously being the most frequently used. They are also alkykating agents and therefore rely on $M G M T$ inactivation for their effect. They were before the TMZ era the chemotherapy treatment of choice. They can cause severe myelosuppression and also pulmonary fibrosis. They are now most often reserved for treatment at progression apart from the PCV combination treatment ${ }^{8,44,57}$.

\section{PCV-Procarbazine, Lomustine, Vincristine}

PCV has in 3 pivotal trials in oligodedroglioma as primary treatment together with RT been shown to provide a substantial survival benefit and is the recommended treatment. It has clearly more adverse effects compared to TMZ, which can lead to dose interruptions or early termination of therapy ${ }^{57,69,70}$. There is an ongoing debate whether TMZ can safely replace $\mathrm{PCV}^{29,71,72}$.

\section{Tumor Treating Fields}

Tumor treating fields (TTF) is a relatively new therapeutic modality. It consists of lowintensity, alternating electric fields delivered via transducer arrays applied to the scalp. In vitro the treatment has been shown to induce cell death and reduce migration and invasion. The electric fields also have an effect on TMZ resistant, unmethylated tumor cells ${ }^{73}$.

\section{Corticosteroids}

Corticosteroid use is an integrated part of glioma treatment, especially for those with high grade glioma, where tumor oedema often aggravates neurological symptoms. It is commonly used in the perioperative period and to diminish radiation induced symptoms. In the palliative setting, to treat tumor associated symptoms, such as seizures, headache, paresis, personality change and cognitive symptoms, steroids can be an effective drug. Side effects of long term steroid use are not negligible, causing for example insomnia, gastro-intestinal bleeding, diabetes, personality change, osteoporosis, muscle dystrophies and increased risk of infections due to immunosuppression ${ }^{74}$. Steroid use has often been found to be associated with worse prognosis in randomized trials, many times in the clinic believed to be due to the disease related factors necessitating its use.

Recent research questions this "dogma" and suggest that corticosteroid treatment itself during radiotherapy can result in shorter survival ${ }^{74,75}$. This finding was also confirmed by analyzing a dexamethasone induced gene signature in TCGA and in an animal model ${ }^{75}$. Lowest possible dose with acceptable symptoms is therefore advocated. 
An alternative to corticosteroids is the anti-VEGF antibody Bevacizumab. Trials with this treatment as adjunct to standard radio-chemotherapy with TMZ failed to improve survival $^{76,77}$. Bevacizumab will though decrease the leakage from the pathological blood vessels in the tumor, thereby decreasing peritumoral oedema and improving neurological functioning ${ }^{78}$. This alternative could be especially important in combination with immunotherapy, but also to avoid steroid induced side effects. It is administered intravenously and is costly, these being limitations for its use.

\section{TREATMENT ACCORDING TO DIAGNOSIS}

\section{Glioblastoma}

Radiotherapy has been shown to prolong survival in randomized trials ${ }^{79-81}$. RT with involved fields, covering the tumor area with a safety margin and providing between 54-60 Gy is standard of care for $\mathrm{GBM}^{80}$. This is delivered in fractions of 1.8-2 Gy per day weekdays for 5-6 weeks.

The addition of concomitant and adjuvant TMZ to RT has been the treatment of choice since $2005^{5}$. TMZ is administered in a daily dose of $75 \mathrm{mg} / \mathrm{m}^{2}$ during RT and followed after one month by up to 6 four weekly cycles of TMZ given in doses of $150-200 \mathrm{mg} / \mathrm{m}^{2}$ days $1-5 \mathrm{in}$ each cycle.

A finding related most often to concomitant and adjuvant RT and TMZ is pseudoprogression $^{82}$. This often occurs on the first radiological examination after radiochemotherapy, were the signs of progression are found. Patients may or may not have clinical symptoms indicating progressive disease in parallel. With further follow-up, during continued treatment, radiological stable disease or regression is found. Pseudoprogression has been shown to be more frequent in patients with $M G M T$ promoter methylated tumor, indicating that it could be a sign of good treatment effect ${ }^{83}$. It seems to be more prevalent in patients with only partially resected tumors ${ }^{84}$.

In a randomized phase 3 trial, tumor treating fields were tested as an adjunct to adjuvant TMZ after the concomitant phase of RT and TMZ. It was shown to confer a survival advantage with median overall survival (OS) being 20.9 months in the TTF + TMZ group versus 16.0 months in the TMZ-alone group (HR, 0.63; 95\% CI, 0.53-0.76; $\mathrm{p}<0.001$ ). The addition of TTF is gradually being introduced internationally as a result of this trial ${ }^{60}$. Patients with good performance status (PS) can be candidates for this treatment after completing concurrent radio-chemotherapy with TMZ, at the start of the adjuvant TMZ phase. The need for special equipment and technical support to the patient together with a high cost contribute to the treatment being implemented stepwise. As the patients need to use the equipment for at least 18 hours per day, and to carry the batteries with them in a backpack, some patients choose to refrain from this therapy.

During the 90's there was much debate regarding the treatment of elderly patients diagnosed with GBM. Expected survival was short, especially in elderly ${ }^{85,86}$. There was a reluctance to treat older patients, due to the timespan of 1.5 months to complete standard RT (SRT), necessitating hospital admission or daily visits. Also the adverse effects of RT were expected to affect the patient for weeks to months after the end of RT, the most common side effects 
being fatigue, concentration problems, irritability and mood changes ${ }^{66}$. This was felt to jeopardize the quality of the short remaining life. Hypofractionated RT (HRT) (higher doses/fraction, over shorter time) was sometimes advocated for elderly GBM patients, but it's efficacy was poorly documented.

During this time the cytotoxic drug TMZ, developed from DTIC, commonly used for malignant melanoma treatment, was being introduced for patients with glioma. As mentioned above, it's side effects are generally tolerable, it passes the blood-brain barrier and is given orally, making it easy to administer.

The Swedish National Brain Tumor Group decided to initiate a study for those 60 years or older, to define the role of active oncological treatment for this patient group. This trial is reported as paper I.

\section{Anaplastic glioma (grade III)}

The German randomized NOA-04 trial investigated the sequence of treatment, comparing RT versus PCV or TMZ in a 2:1:1 randomization, for mixed grade III glioma. At progression or toxicity leading to the need to stop the ongoing therapy, patients switched to the opposing treatment modality, with a new random assignment to $\mathrm{PCV}$ or $\mathrm{TMZ}^{71}$. Long term results showed comparable outcome with both approaches. Molecular markers were of importance and for those with G-CIMP and 1p/19q codeleted tumors PCV led to longer progression free survival (PFS) than TMZ treatment (HR PCV vs TMZ $0.39(0.17-0.92), \mathrm{p}=0.031)^{72}$.

\section{Anaplastic oligodendroglioma (grade III)}

For grade III anaplastic oligodendroglioma two important randomized trials have after long term follow up resulted in treatment recommendations. These are the Radiation Therapy Oncology Group (RTOG) 9402 and the European Organization for Research and Treatment of Cancer (EORTC) 26951 trials that were initiated in the 90`s. While the primary analyses failed to show any difference for the addition of PCV chemotherapy to RT, reanalyses of the two trials, published in 2013, found a significant survival benefit for the addition of PCV, either administered before (RTOG 9402) or after RT (EORTC 26951) ${ }^{57,70}$. As these trials were initiated before molecular markers of oligodendroglioma had been established, those included could apart from harboring a tumor with IDHmut and 1p/19q codeletion, also have IDHwt or non-codeleted tumors. Molecular analyses reported in 2014, revealed that PCV effect was associated with IDH mutations ${ }^{56}$.

\section{Anaplastic astrocytoma (grade III)}

The RTOG 9813 trial for anaplastic astrocytoma (AA) compared RT with PCV versus RT with TMZ and found no significant survival difference, although the study was closed prematurely due to slow accrual. IDHmut were shown to be prognostic for OS. TMZ was found to be a less toxic therapy compared to $\mathrm{PCV}^{87}$.

A trial focusing on patients with AA (grade III), without $1 p / 19 q$ codeletions, was initiated before the role of IDH mutations was evident, the CATNON (Concurrent and/or adjuvant TMZ for $1 \mathrm{p} / 19 \mathrm{q}$ non-codeleted tumors) trial ${ }^{88}$. This trial aims at defining the effect of TMZ together with RT for this patient group, investigating the role of both adjuvant and concomitant TMZ. Preliminary results, reported in 2017, confirmed a significant effect of the 
addition of adjuvant TMZ. Preliminary molecular analyses were reported at ASCO and EANO 2019. The survival benefit of the adjuvant TMZ could now be shown to correlate to IDHmut ( $\mathrm{p}<0.001$ and HR=0.46). For the concomitant TMZ treatment, for the whole study cohort no benefit was found ( $\mathrm{p}=0.46$ and HR 0.93 ), but in the IDHmut subgroup a significant impact on survival was noted ( $\mathrm{p}=0.012$ and $\mathrm{HR}=0.63$ ). For those $M G M T$ methylated, both the concurrent and adjuvant TMZ increased survival (Personal communication M van den Bent).

\section{Low-grade glioma (grade II): diffuse astrocytoma and oligodendroglioma}

The role of surgery and it's timing for low grade glioma was an ongoing debate during a long time. While some advocated watchful waiting, others propagated for early surgical intervention. In the absence of a randomized trial, a Norwegian group compared survival for patients diagnosed with low grade glioma treated at either a center with watchful waiting or early intervention. OS for watchful waiting was 5.8 years versus 14.4 years for early resection $(\mathrm{p}<0.01)$. Also after adjustment according to molecular markers the survival difference in relation to surgical strategy was maintained $(\mathrm{p}=0.001)^{89}$.

For grad II glioma also a number of pivotal randomized trials have been conducted. Two studies focused on RT dose, comparing low versus high dose. The EORTC 22844 trial studied the comparison of 45 Gy in 25 fractions to 59.4 Gy in 33 fractions. No difference in PFS or OS were found, although those in the high dose arm reported more RT side effects ${ }^{90}$. A North American trial randomized patients between 50.4 Gy delivered in 28 fractions or 64.8 Gy in 36 fractions. Survival at 5 years was $73 \%$ for low dose versus $68 \%$ for high dose $\mathrm{RT}^{91}$. Recommended RT dose according to the Swedish national guidelines is 50.4-54 Gy ${ }^{67}$.

The EORTC 22845 study compared early versus late RT (at first progression). A benefit for early RT was found regarding PFS, but no difference in OS, when RT was administered at recurrence ${ }^{92,93}$. A reason to delay $\mathrm{RT}$ in these often young patients with expected long survival is the risk of late radiation induced cognitive decline.

The prognostic factors identified in these trials were age ( $>$ or $<40$ years), extent of resection and histological subtype, with astrocytoma having the worst outcome ${ }^{93}$.

An additional trial, the RTOG 9802, established the combination of adjuvant PCV and RT as standard of care, as adding PCV led to significantly better both PFS and OS compared to RT alone for those with high-risk low grade glioma ${ }^{69,94}$.

An EORTC trial (22033-26033) conducted before the results of the RTOG 9802 trial were known, randomized patients with high risk low grade glioma to RT versus TMZ as first line treatment. Data regarding PFS have been published and did not show any significant difference between RT and TMZ, with median PFS being 46 vs 39 months respectively $(p=0.22)$. The subgroup of IDHmut non-codeleted tumor patients though had a significantly longer PFS when treated with RT ( $\mathrm{p}=0.0043$ ). The trial also confirmed previous findings that those with codeleted tumors have the most favorable outcome as compared to those with IDHmut non-codel, and that patients with IDHwt tumors had the worst prognosis. Follow-up is still ongoing regarding $\mathrm{OS}^{34}$. 
Some questions still unanswered are the timing of RT plus PCV, if it is safe to treat with chemotherapy alone and defer RT together with additional chemotherapy until first progression and if PCV can safely be replaced by TMZ. Some of these questions will be answered by the CODEL trial (regarding $1 \mathrm{p} / 19 \mathrm{q}$ codel tumors grade II-III) and the EORTC IWOT trial exploring "wait or treat" with RT and TMZ for IDHmut non-codeleted grade IIIII astrocytoma.

Also, now with the molecular profile of the tumors being determined before inclusion into a clinical trial, future studies can focus on patients with "the correct" diagnosis, with expected similar biological behavior. This might, at least partly, alter the results compared to older trials.

\section{Treatment at recurrence/progression}

Treatment options at recurrence/progression rely mainly on what therapy the patient has received in the initial phase of disease. Other important factors to consider are the time elapsed since primary treatment and the extent and pattern of recurrence, together with the patient's performance status, guiding what therapy he/she is expected to tolerate. Often the $M G M T$ status of the tumor will be included in the therapeutic discussion, as patients with unmethylated tumor are not expected to respond to alkylating agent therapy. For those with methylated MGMT and previous TMZ treatment, a nitrosourea compound, most often lomustine, seems to be in use ${ }^{8}$.

\section{Conclusion treatment of glioma}

In conclusion, for all grade III 1p/19q non-codeleted and grade IV glioma radiotherapy and adjuvant chemotherapy with TMZ are standard of care, for GBM also concomitant, except for patients not deemed fit enough to tolerate combined treatment. Treatment, especially for GBM, is to start as soon as possible after diagnostic surgery ${ }^{41}$.

For IDHmut 1p/19q codeleted glioma (oligodendroglioma), RT together with PCV is the treatment of choice, although PCV is often substituted for TMZ for toxicity reasons ${ }^{29}$.

Correct diagnosis and molecular profiling is vital for prognostication, and optimal use of available treatments. For inclusion into clinical trials molecular markers are crucial.

\section{PATIENT CARE BEYOND TUMOR SPECIFIC TREAMENT}

Brain tumors patients have a bad prognosis and the disease often carries additional hardships compared to other cancers. Apart from being a threat to the patient's life, they cause neurological and cognitive decline along the disease trajectory and personality changes are also common. Treatment of patients with cancer, including brain tumors, is more than providing the correct tumor specific therapy. In overall patient care focus should also be given to aspects such as communication, information, a patient-centered approach to treatment decision-making and support of both patient and family ${ }^{95}$. How these central parts of care are best performed is not as often studied as medical therapies, and therefore evidence-based care can be improved. For example, how detailed information brain tumor patients want to receive in case of a very negative prognosis is poorly examined. 
In recent times, no study has investigated the experiences of brain tumor patients in the Swedish health care setting. Therefore, we conducted a qualitative study, where glioma patients were interviewed regarding their experience of and preferences for information on diagnosis and prognosis, and about their involvement in the treatment decision process. We also inquired about how detailed information they would like to be given in the scenario of no treatment being available / prognosis being very poor. In all, 25 patients with both high-grade (mainly GBM) and low-grade glioma were included after primary surgery, and were interviewed according to a manual containing the research questions.

The analysis of the interviews resulted in three themes, "Finding out about the tumor", "Deciding about treatment" and "The truth about prognosis". The main finding was that patients have different expectations and requests. For each theme we could identify patients having a variety of experiences and whishes regarding how much prognostic information they received or how involved they wanted to be in the treatment decision process. All patients expressed that they wanted to be told the truth, but they had different perceptions of what the truth was; for some it was detailed information, for others more a general idea, while still others just wanted the good news and have the bad news omitted (Table 2.). Our patients expressed, that they wanted negative prognostic information to be given gradually, allowing to adjust to the truth at their own pace.

\begin{tabular}{|l|l|l|}
\hline \multicolumn{1}{|c|}{ The good truth } & \multicolumn{1}{|c|}{ The truth without details } & \multicolumn{1}{c|}{ The whole truth } \\
\hline Only positive information & No details & $\begin{array}{l}\text { The complete prognosis even } \\
\text { though it hurts }\end{array}$ \\
\hline Omit bad information & $\begin{array}{l}\text { Information of the overall } \\
\text { picture }\end{array}$ & $\begin{array}{l}\text { Detailed information to allow } \\
\text { for acceptance }\end{array}$ \\
\hline $\begin{array}{l}\text { Better not to know bad } \\
\text { prognosis }\end{array}$ & Hope can be preserved & To be able to plan your life \\
\hline $\begin{array}{l}\text { Negative information leads } \\
\text { to loss of hope }\end{array}$ & $\begin{array}{l}\text { To be able to inform your } \\
\text { family }\end{array}$ \\
\hline $\begin{array}{l}\text { Absence of hope could make } \\
\text { you die faster }\end{array}$ & $\begin{array}{l}\text { To be able to choose how to } \\
\text { live the rest of your life }\end{array}$ \\
\hline
\end{tabular}

Table 2. Reasons and requests regarding how the truth should be conveyed for the three categories for the theme "The truth about prognosis"

An unexpected finding was the reports of distress of those who had come across their diagnosis when searching for other information in their electronic medical records that now have been made available to the patients.

Our conclusions are that patients need individualized information and participation in medical decision making, which is supported by previous publications in cancer and also in brain tumor patients ${ }^{3,96-98}$. To allow for personalized information, several studies found that 
the patient needs to be asked about how detailed information they want. That the requirement for information can change over time has also been reported ${ }^{3,96,99}$.

We believe there is a need to further discuss if and how sensitive information that the patient has not yet received at a personal consultation should be documented in the electronic medical record. Regarding the medical decisions made, it is important that patients are involved to the extent they prefer themselves, so that therapy can be adjusted according to their wish.

This study is in the final phase of analysis and manuscript preparation.

\section{NATIONAL GLIOMA CARE}

\section{The Swedish National Brain Tumor Group (SNBTG)}

The SNBTG was initiated in 1993, with the aim to develop and harmonize treatment of brain tumor patients in Sweden and to also facilitate the conduct of clinical trials. An early study performed by the SNBTG was the randomized trial exploring the addition of Estramustine to standard $\mathrm{RT}^{100}$.

The SNBTG was part of a Scandinavian collaborative group, called the Nordic Clinical Brain Tumor Study Group (NCBTSG). This group conducted the two clinical trials reported in this thesis, namely the Nordic trial on elderly patients (>60 years) with GBM (paper I) and the Neoadjuvant trial for patients 60 years or younger with grade III astrocytoma or GBM (paper II).

Other efforts of the SNBTG are the Swedish Quality Registry for patients with primary brain tumors $(\mathrm{SNQR})^{1}$ and the National Guidelines for treatment of patients with primary brain and intraspinal tumors ${ }^{67}$.

\section{The Swedish National Quality Registry for Primary Brain Tumors (SNQR)}

The aims of the SNQR are to contribute to better care for brain tumor patients, and to clinical studies. The SNQR also provides a foundation for work with quality assurance, and for compiling national brain tumor statistics ${ }^{1,27}$

The registry was launched in 1999 , covering all patients with the primary intracranial tumors glioma and meningioma, from the six regions of Sweden. Coverage of the reports has varied in the different regions, but has generally improved over time. Since 2009 also postsurgical treatment of glioma patients are reported. With start in 2016, patient reported outcome (PROM) and experience (PREM) measures are included as well. From 2019, the updated electronic report system is additionally collecting data on important molecular markers and all oncological therapies. Also further primary CNS tumors are included.

The first report from the SNQR was compiled after 7 years of data collection (1999-2005). The most important finding was discrepancies in diagnosing glioma between different regions, where the fraction of GBM varied between $43-73 \%$ of all glioma ${ }^{101}$. This led to consensus meetings among the national neuropathologists. An improvement could be noted, as during the period 2011-2016 the diagnosis of GBM was more congruent, with a variation between $62-71 \%{ }^{1}$. 
In the SNQR data are available on prognostic factors, such as preoperative performance status, age, gender and type of surgery. The data have allowed for comparison of treatment strategies in the different health care regions, for example regarding patient selection for surgical interventions. Differences, mainly in the fraction of elderly patients that receive surgery and also in the type of surgery performed, were uncovered. Also waiting times, such as time from surgery to initiation of oncological treatment, differ between regions ${ }^{1,27}$.

A strength of the SNQR is that the cross regional comparisons allow for national discussions regarding noted differences, thereby increasing the possibilities to achieve optimal, equal and up to date glioma treatment for all Swedish patients, as noted for example by the improvement in pathology for GBM.

Another important aspect of the registry is the possibility to evaluate the impact of changes in therapeutic interventions over time. An improvement in survival for GBM patients on a national level was noted after the introduction of concomitant radio-chemotherapy with TMZ, which started 2005. A substantial improvement in survival for those 60-84 years old with high grade glioma was found as well, indicating increased therapeutic activity for these patients compared to the early years of the registry ${ }^{102,103}$.

Gender issues in general, but also in cancer specifically have gained increased attention in the last years. Data from the SNQR show that there is no difference regarding surgical interventions between men and women in Sweden ${ }^{1}$. Some gender related differences were identified, such as in median age at diagnosis for high grade glioma (grade III and IV), tumor localization and preoperative performance status (Poster P01.151 EANO 2018) ${ }^{1}$.

This database constitutes a unique resource for research also for correlation of the reported data to molecular markers in the patient's tumor. The latter has been an important aspect in our work, where we since 2008 have collected patient informed consents, tumor specimens, either fresh frozen or paraffin embedded, normal tissue, mainly blood samples and have studied the importance of different molecular markers on outcome. The findings have been correlated to data in the SNQR regarding prognostic factors and/or treatment. The SNQR has also been an invaluable resource for selecting patients for different projects on the basis of diagnosis, prognostic factors and/or treatment provided ${ }^{35,104}$. 


\section{Aims}

The aim of the studies in this thesis is to contribute to the improvement of care of glioma patients, mainly focusing on therapeutic interventions including MGMT assessment in the clinic.

\section{Specific aims}

\section{Paper I}

To investigate the optimal palliative treatment for patients $\geq 60$ years with newly diagnosed GBM by comparing three different treatment alternatives, standard radiotherapy $60 \mathrm{~Gy}$, hypofractionated radiotherapy 34 Gy or the alkylating agent TMZ, regarding survival, safety and QoL.

To assess the role of $M G M T$ promoter methylation status for outcome for TMZ treatment and radiation therapy.

\section{Paper II}

To investigate the role of TMZ treatment administered postoperatively for 2-3 cycles before standard radiotherapy in patients with newly diagnosed grade III astrocytoma or grade IV glioblastoma, 60 years or younger, compared to standard radiotherapy treatment alone, regarding survival and safety.

To evaluate the contribution of different molecular markers to outcome, specifically IDH mutations and MGMT promoter methylation.

\section{Paper III}

To investigate which methods and cut-offs for testing MGMT status in the clinical setting that are in use worldwide.

To investigate the opinions of those working with MGMT testing in the clinic regarding the need of international guidelines on methods and cut-off. 


\section{Patients/respondents and methods}

\section{Paper I}

The Nordic elderly study was initiated by the SNBTG and was before start of inclusion extended to the NCBTSG. Later, a number of centers from the EORTC joined the trial. Patients were recruited from Sweden, Norway, Denmark, Austria, France, Switzerland and Turkey, in all, 28 centers.

Standard of care for younger patients was at this time 60 Gy RT (SRT) over 6 weeks, which was often not provided to those over 60 years, due to expected short survival. A shorter RT course, with less time hospitalized or an outpatient treatment was believed to be a better palliative treatment, but lacked documented efficacy from a randomized trial. For these patients QoL was considered to be of special importance, to facilitate the comparison of length of survival to its quality.

Method: Randomized phase III trial

\section{Study procedures}

Patients were randomized between SRT 60 Gy over 6 weeks (30 fractions), HRT 34 Gy over 2 weeks (10 fractions) or TMZ at conventional dosing, $200 \mathrm{mg} / \mathrm{m}^{2}$ days $1-5$ every 28 days. Some centers did not provide SRT to patients $>60$ years and these centers were allowed to randomize between only HRT and TMZ for all their included patients.

Inclusion criteria were newly diagnosed patients $\geq 60$ years old, with a histologically confirmed GBM. Those with PS WHO 0-2 were eligible or PS 3, if this was caused only by neurological deficit, the latter to resemble patients seen in the clinic. Adequate hematological, renal and liver function was also required.

Randomization was stratified by study center.

Patients were followed with the EORTC QoL questionnaire QLQ-30 with the Brain cancer module BN-20. They were also monitored for survival and adverse events.

Due to the publication of the results of concomitant and adjuvant RT plus TMZ ${ }^{5}$, after October $15^{\text {th }} 2004$, patients younger than 65 years fit for combined treatment were excluded.

In all, 342 patients were randomized.

\section{Pathology review and molecular testing}

Due to the difficulties in correctly diagnosing glioma according to the WHO criteria used at this time, a central review of the diagnosis was done in Lausanne by Dr Benoit Lhermitte for all tumors where it was possible to acquire tissue. MGMT methylation status had been documented as a possible predictive and/or prognostic factor for treatment with alkylating agent therapy and was therefore included in the analysis post hoc. This analysis was conducted by quantitative msPCR. 


\section{Primary and Secondary endpoints}

The primary endpoint was OS from the date of randomization. Secondary endpoints were health-related QOL and safety. Survival according to $M G M T$ methylation status was added at the time of final analyses.

\section{Statistical analyses}

In this trial survival was calculated using the Kaplan-Meier method with a two-sided log-rank test, Cox's regression analysis for pairwise comparisons and for calculation of hazard ratios (HRs) for relative risk of death. Survival was calculated according to treatment arm and/or MGMT methylation status. Multivariate analysis was used to investigate the influence of known prognostic factors. Interactions between treatments and prognostic factors was also tested. For comparison of $2^{\text {nd }}$ line treatment $\chi^{2}$ test was used. For comparison of delivered RT doses by age group Fisher's exact test was utilized ${ }^{105}$.

For health-related QoL, changes in mean scores from baseline values to follow-up at 6 weeks and 3 months for each treatment group were calculated. The Kruskal-Wallis test and pairwise comparisons with the Mann-Whitney U test were utilized ${ }^{105}$.

The significance level was $\mathrm{p}<0.05$. Analyses were conducted by intention to treat.

\section{Trial registration}

The trial is registered, number ISRCTN81470623.

\section{Paper II}

At the time of initiation of the Neoadjuvant study, 60 Gy RT was standard of care for patients with high grade glioma, including both grade IV (GBM) and grade III tumor patients. Although not yet proven, it was believed that TMZ would have a place in early treatment of high grade glioma. A pilot study conducted in Copenhagen by Dr Hans Skovgaard Poulsen investigated TMZ for 2-3 cycles after surgery before start of RT in newly diagnosed patients with grade III or IV glioma. They found that, compared to historical controls, patients had unexpectedly long median survival, exceeding 27 months. It was therefore decided that a randomized trial, by the NCBTSG, should explore this new approach, and include patients 60 years or younger. Thirteen centers from Sweden, Norway, Denmark and Finland took part in the study.

Method: Randomized trial

\section{Study procedures}

Patients were randomized between SRT 60 Gy over 6 weeks or the same RT preceded by 2-3 cycles of TMZ (NeoTMZ) at standard dosing, $200 \mathrm{mg} / \mathrm{m}^{2}$ days $1-5$ every 28 days.

Inclusion criteria were newly diagnosed patients, with histologically proven GBM (grade IV) or anaplastic astrocytoma (grade III, AA), age 18-60 years, PS WHO 0-2, life expectancy of 
$>3$ months, and adequate hematological, renal and liver function. Patients with prior surgery for grade 2 glioma recurring as grade III or IV were eligible.

Randomization was stratified by study center.

Due to the publication of the results of concomitant and adjuvant RT plus $\mathrm{TMZ}^{5}$, the protocol was amended to include concomitant TMZ together with RT for all patients after March 2005. In all, 145 patients were randomized.

\section{Molecular testing}

For all tumors, where it was possible to acquire tissue, molecular markers were investigated that at the time of this analyses had been documented could have an impact on diagnosis and/or outcome. Immunohistochemistry was conducted at the Department of Pathology, Odense University Hospital, Denmark and the analyses of extracted DNA at the Department of Cell Biology, Linköping University. The markers investigated were $I D H 1$ and $I D H 2$, codeletion of 1p/19q, loss of ATRX, p53 mutations and MGMT methylation status.

\section{Primary and Secondary endpoints}

The primary endpoint was OS from the date of randomization. The secondary endpoint was safety. Survival according to molecular markers was added post hoc at the time of final analyses.

\section{Statistical analyses}

According to protocol, survival analyses included the complete study cohort, subgroups GBM and AA as well as treatment without or with concomitant TMZ (early vs. late inclusion).

Survival was estimated by the Kaplan-Meier method and a two-sided log-rank test. Hazard ratios (HRs) were calculated by Cox regression analysis and for pairwise comparisons by logrank tests. Multivariate analysis for all patients included diagnosis, known prognostic factors, baseline steroids and treatment arm. An additional multivariate analysis included MGMT promoter methylation status (methylated vs. unmethylated tumor) and IDH status (mutated vs. wildtype). For comparison between groups, Fischer's exact test was used ${ }^{105}$.

The significance level was $\mathrm{p}<0.05$. Analyses were conducted by intention to treat.

\section{Trial registration}

The study is registered ISRCTN45209900.

\section{Ethical aspects regarding paper I and II}

The study protocols for the Nordic and the Neoadjuvant trials were approved by Ethics Committees of all participating countries and for all centers. All patients signed written informed consent. 


\section{Paper III}

Different methods and cut-offs are available for MGMT testing. To evaluate if this constitutes a problem in the clinic worldwide, we decided to conduct an international survey regarding $M G M T$ methylation analyses.

Method: Study analyzing data collected from a survey

\section{Study procedures}

A questionnaire with 27 queries regarding MGMT testing was compiled, investigating different aspects. Opinions regarding international guidelines were additionally collected. The respondents were encouraged to contribute with their own comments.

The survey was electronically sent to national and international neuropathology groups and to others known to work in the field. The survey was forwarded by the neuropathology groups to the members. The number of members that received the survey is not known.

The responses were returned electronically. In all, 152 respondents answered the survey.

\section{Statistical analyses}

For each question percentages for each answer was calculated. For questions allowing more than one answer total can be $>100 \%$.

\section{Ethical aspects}

As no patients were involved in this study, we did not identify any ethical dilemmas. 


\section{Results and Discussion}

\section{Paper I}

In paper I (The Nordic trial) we report on a study that compared SRT over six weeks to 60 Gy (control arm) to HRT over two weeks (10 fractions á 3.4 Gy to 34 Gy) or TMZ given in up to six 4 weekly cycles $(200 \mathrm{mg} / \mathrm{m} 2$ day $1-5$ every 28 th day) in patients 60 years or older.

In all, 342 patients were included.

Pairwise comparisons of survival were conducted between treatment arms. For the comparisons with SRT, the 291 subjects randomized between all three treatment arms were included. Those randomized to TMZ had superior survival compared to 60 Gy RT (Figure 4.). There was no significant difference between HRT versus 60 Gy SRT. For the subgroup of patients $>70$ years old, both TMZ and HRT were superior to SRT. For the comparison HRT versus TMZ, including the additional 51 patients randomized only between these two treatment arms, there was no significant difference. QoL data suggested that those randomized to TMZ had better quality of life.

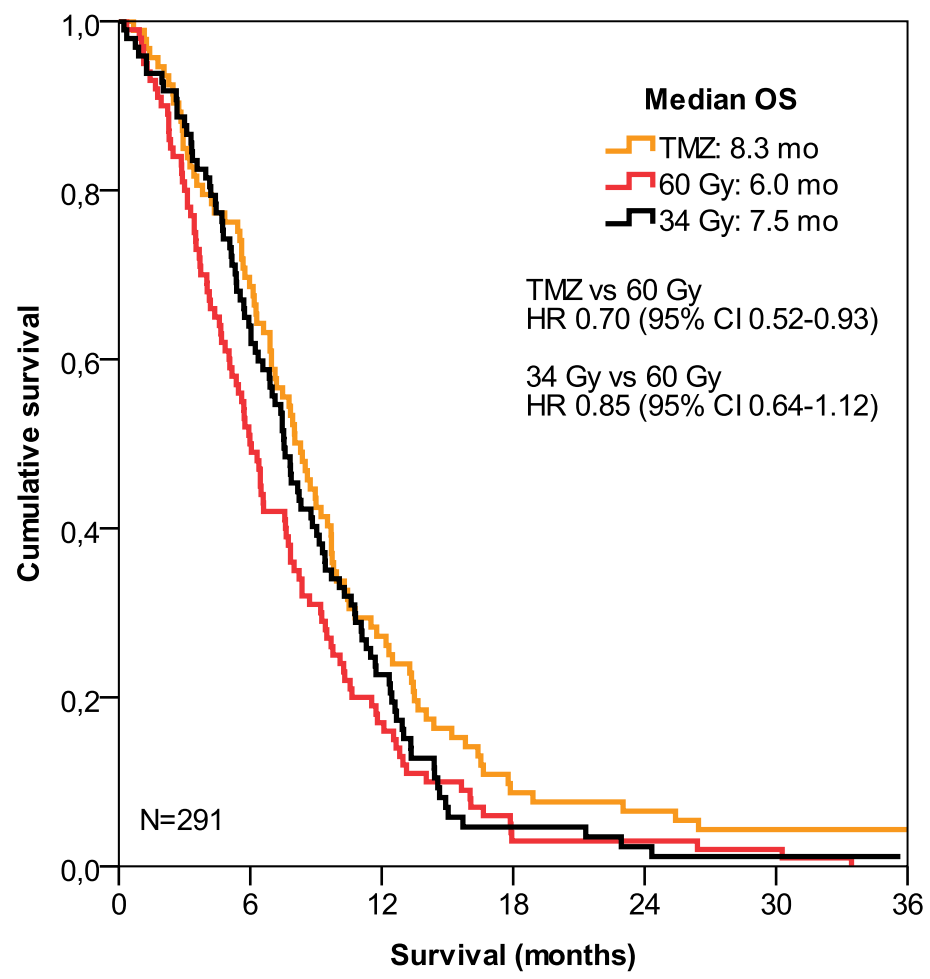

Figure 4. Overall survival for all patients randomized between all three treatment arms. TMZ=Temozolomide, $60 \mathrm{~Gy}=60 \mathrm{~Gy}$ radiotherapy, $34 \mathrm{~Gy}=34 \mathrm{~Gy}$ radiotherapy, OS= Overall survival, $\mathrm{mo}=$ months, $\mathrm{HR}=$ Hazard ratio, $\mathrm{CI}=$ Confidence interval, $\mathrm{N}=$ numbers of patients , vs=versus Reprinted with permission from reference ${ }^{40}$. 
MGMT status could be assessed in tumor tissue for 203 patients. It was shown that in the TMZ arm, those with MGMT methylated tumor had significantly better survival than those with unmethylated tumor. Those with unmethylated tumor and TMZ treatment seemed to have the poorest survival, although not significantly worse than for those receiving RT (SRT and HRT combined) (Figure 5.). For the effect of RT, the methylation status of $M G M T$ was not found to be of importance.

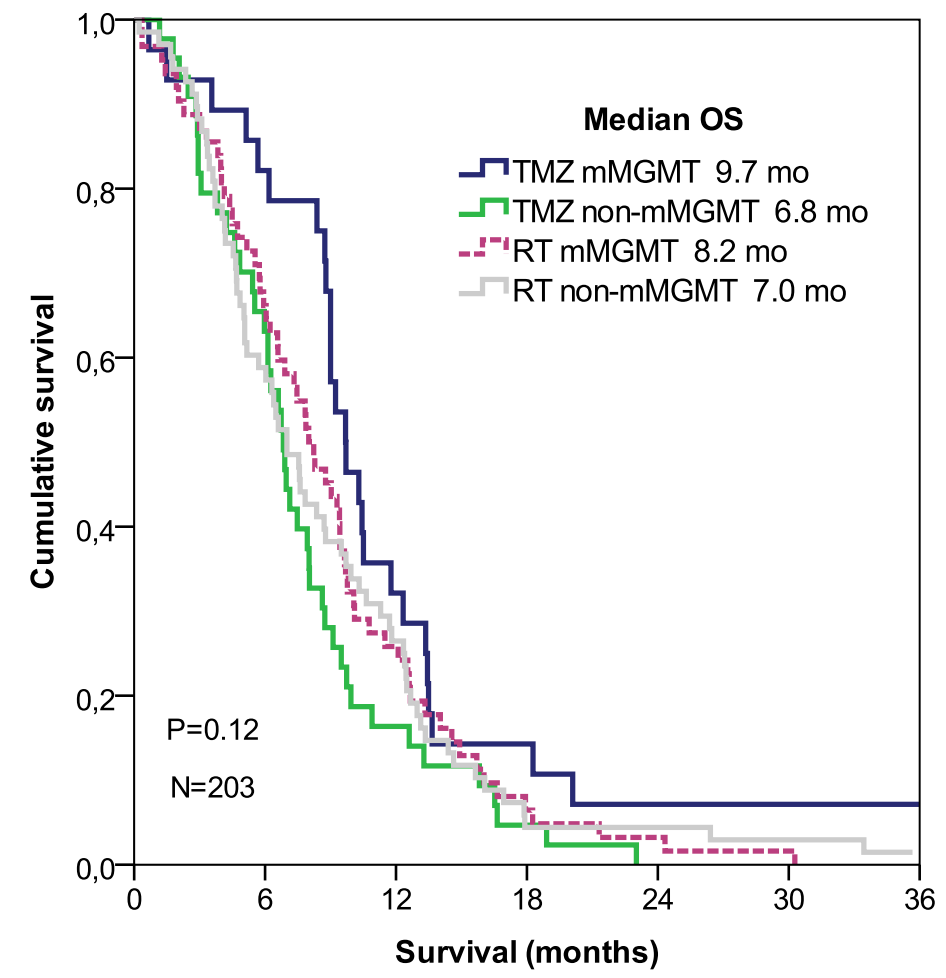

Figure 5. Overall survival for all randomized patients according to treatment arm TMZ or RT (SRT and HRT combined) and MGMT methylation status.

TMZ=Temozolomide, $\mathrm{RT}=$ radiotherapy, $\mathrm{mMGMT}=$ methylated $M G M T$, non-mMGMT=unmethylated MGMT, $\mathrm{OS}=$ Overall survival, $\mathrm{mo}=$ months, $\mathrm{N}=$ numbers of patients

Reprinted with permission from reference ${ }^{40}$.

A shortcoming of this trial was that the intended number of patients $(n=480)$ were not included. The power of the comparisons between SRT and the other treatment arms is therefore $\approx 70 \%$, instead of the planned $80 \%$. The study design, to allow some centers to randomize patients only between two of the three treatment arms is unusual and can be criticized. For the statistical analyses this was taken into consideration. An advantage was that the extra patients in the two-arm randomization did allow for better power for the comparison between HRT and TMZ (power $\approx 80 \%$ ). Furthermore, the long inclusion time of nearly 10 years could be debated, however the long follow-up allowed for more events to occur. 
While the Nordic trial was ongoing two trials investigating different aspects of RT for elderly with GBM were published. A third RT study was reported in 2015.

A French trial provided evidence that also patients $>70$ years benefit from RT, administered to $50 \mathrm{~Gy}$ in $1.8 \mathrm{~Gy}$ fractions, as compared to best supportive care alone. Survival was increased from 16.9 weeks to 29.1 weeks, with HR for death in the RT group being 0.47 $(95 \% \text { CI, 0.29-0.76; } \mathrm{p}=0.002)^{81}$.

A randomized trial from Canada published in 2004 compared standard 60 Gy RT versus 40 Gy in 15 fractions over 3 weeks in 100 patients over 60 years old and found no difference $(\log \text { rank } \mathrm{p}=0.57)^{106}$. They followed up with a trial comparing the same hypofractionated scheme to an even more abbreviated RT course of $5 \times 5$ Gy over one week in elderly and/or frail patients. No difference in survival was found $(\mathrm{p}=0.988)^{107}$.

The results of the Nordic study were congruent with the German NOA-08 trial comparing TMZ to RT over 5-6 weeks in those 65 years or older, reported at the same time ${ }^{42}$. The Nordic trial additionally indicated superiority of HRT over SRT for the eldest.

The NORDIC and NOA-08 trials were followed by an international study, initiated in Canada, that examined the role of combined treatment of HRT and concomitant and adjuvant TMZ, contra HRT only, using the 3 week 40 Gy schedule, in patients 65 years or older. The pivotal study by Stupp et al from 2005, examined patients 70 years or younger, who were randomized to $60 \mathrm{~Gy}$ SRT with or without concomitant and adjuvant $\mathrm{TMZ}^{5}$, resulting in superior outcome for the combined treatment. Therefore not unexpectedly, in the Canadian study for those 65 years or older, with PS 0-2, the combination of RT and TMZ was shown to be superior. The role of $M G M T$ methylation for survival and especially for PFS, was confirmed $^{43}$.

A key finding for the trials above were the superiority of TMZ as compared to RT, but only for those with a methylated tumor MGMT promoter. It must also be considered an advantage to be able to provide HRT to those with unmethylated $M G M T$, thereby minimizing time spent in hospital, with equal or better outcome regarding survival than with SRT.

Due to these trials the EANO has suggested that for those $>70$ years, RT should be provided if $M G M T$ is unmethylated, while those with methylated $M G M T$, and not being fit for combined treatment with RT and TMZ, should be offered TMZ alone ${ }^{8}$.

An ongoing collaboration, headed by the respondent, relates to a meta-analyses of the three randomized trials on elderly investigating RT and TMZ, the Nordic ${ }^{40}$, the NOA- $08^{42}$ and the Canadian studies ${ }^{43}$. The EORTC brain tumor group is responsible for the statistical analyses. The main focus is the role of comorbidities for outcome, so as to be able to better guide treatment recommendations. Another aim is to define a clinically valid cut-off for $M G M T$ methylation when analyzed by quantitative msPCR in this patient group, which was utilized for all three trials ${ }^{40,42,43}$ 


\section{Paper II}

This paper reports on the Neoadjuvant trial, a second randomized study of the NCBTSG exploring NeoTMZ for 2-3 four weekly cycles before the start of SRT, compared to SRT alone. Due to the inherent difficulties and subjectivity in grading tumors as astrocytoma grade III or GBM according to the WHO criteria at this time, both grades were included. Apart from codeletions of $1 \mathrm{p}$ and $19 \mathrm{q}$, prognostic or predictive molecular markers of proven clinical significance had not yet been determined. As patients $\geq 60$ years were being recruited to the Nordic elderly trial by the NCBTSG and these patients were not believed to be candidates for extensive treatment, this trial included patients 60 years or younger.

In all, 145 patients were enrolled in the study.

The importance of molecular markers was recognized by the end of the trial, therefore, where possible, tumor tissue was collected retrospectively (112 patients).

For the primary endpoint, survival for SRT versus NeoTMZ in the whole study cohort, there was no significant difference, thereby not achieving the primary objective (Figure 6.).

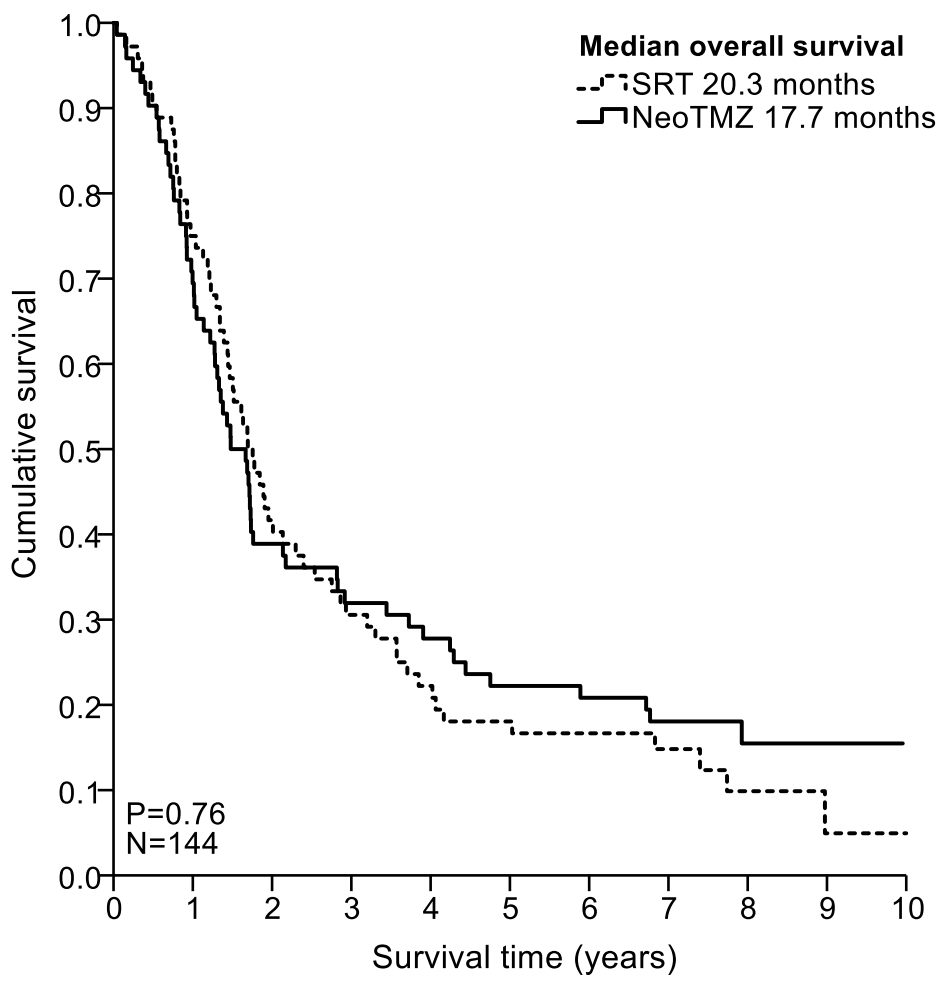

Figure 6. Median overall survival for the whole study cohort.

SRT=standard radiotherapy, NeoTMZ= Neoadjuvant TMZ followed by RT, N=numbers of patients. Reprinted with permission from reference ${ }^{41}$. 
For the subgroup analyses, for those randomized as AA $(n=41)$, median OS was significantly better for NeoTMZ, being 5 years longer, than for SRT (Figure 7.). It was presumed that this difference could be due to IDH mutations in the tumor of some of the patients in the AA cohort. Molecular analyses for IDH was possible for 107 patients, and 20 were confirmed as IDH1 mutated. Survival analysis for the IDH mutated cohort showed median OS of 48.8 months for SRT, while for NeoTMZ median OS had not been reached and was estimated to be $>100$ months. Probably due to the small numbers, this did not reach statistical significance. For those included as GBM there was no advantage with the neoadjuvant treatment. For $78 \mathrm{GBM}$ patients with methylation status of the MGMT promoter determined, we found the best survival for MGMT methylated patients in the SRT arm and an unexpectedly poor survival for MGMT methylated patients allocated to NeoTMZ, however numbers are small for each group. For those with IDH wildtype tumor there was also no advantage of NeoTMZ.

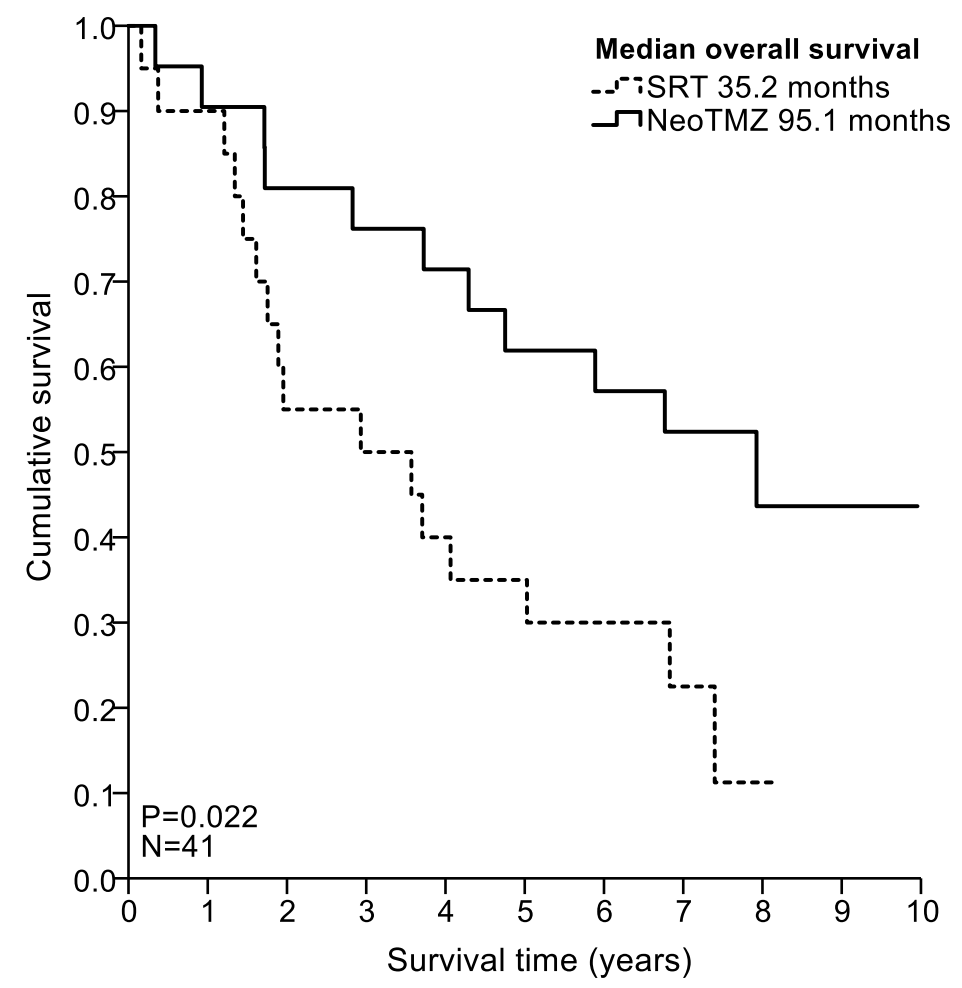

Figure 7. Median overall survival for the Anaplastic astrocytoma (AA, grade III) cohort. SRT=standard radiotherapy, NeoTMZ= Neoadjuvant TMZ followed by RT, N=numbers of patients. Reprinted with permission from reference ${ }^{41}$.

Although this study has several shortcomings, it does provide some valuable information on treatment of glioma with neoadjuvant TMZ. While the study was ongoing, important changes in treatment recommendations took place, necessitating changes in study design, to incorporate concomitant $\mathrm{TMZ}$ with $\mathrm{RT}^{5}$. There were developments in molecular diagnostics 
in glioma, identifying important differences between IDHwt and IDHmut tumors ${ }^{4}$. The number of patients planned $(n=322)$ was not reached as the trial closed prematurely after including the number of patients planned for the first interim analysis $(n=145)$. This was due to slow accrual. The interpretation of our findings need to be done with caution, especially for subgroup analyses. Molecular analyses were done post hoc.

We hypothesized that neoadjuvant TMZ would be beneficial for patients with high grade glioma (AA and GBM), when taking into account factors such as the common delay between surgery and the start of RT of up to 7 weeks ${ }^{1}$, where tumor progression sometimes can be seen in the clinic. TMZ can often be initiated faster, shortening the time between surgery and start of tumor specific treatment. For those with GBM or IDH wildtype glioma this was not the case. Not even those with $M G M T$ promoter methylated tumor and 2-3 cycles of neoadjuvant TMZ did better than those in the SRT arm. Instead there was a trend towards inferior survival for the NeoTMZ approach. This indicates that for these glioma patients RT should not be delayed, at least not for 2-3 months.

We found that for those included with the diagnosis of AA there was a substantial prolongation of survival if they received chemotherapy with TMZ before RT. This is in line with the updated findings in two randomized trials, although these focused on anaplastic oligodendroglioma and PCV chemotherapy. The RTOG 9402 and the EORTC 26951 trials examined the role of PCV before and after RT respectively ${ }^{57,70}$. One important point is that PCV both before or after RT had a positive effect on survival, indicating that both approaches can be valid. As molecular diagnostics have evolved in the last 20 years, it could be presumed that these studies that started accrual in the 90's, would include a mixed population of IDH wildtype and IDH mutated tumor patients, the latter with or without codeletion of $1 \mathrm{p} / 19 \mathrm{q}$, thereby also including patients similar to those in the AA cohort of the Neoadjuvant trial. IDH mutational status was also reported to be of importance for the response to $\mathrm{PCV}^{56}$.

In the CATNON trial, anaplastic glioma without $1 \mathrm{p} / 19 \mathrm{q}$ codeletions were included and the role of concomitant and adjuvant TMZ investigated. Preliminary results were published in 2017 and showed a survival benefit for the addition of adjuvant TMZ in 12 cycles, while the role of concomitant TMZ needed longer follow up ${ }^{88}$. In our study, 2-3 cycles of neoadjuvant TMZ for AA patients resulted in a 5 year survival prolongation compared to SRT, from 35 to 95 months, despite many patients in the SRT alone arm receiving concomitant TMZ. This might indicate that 2-3 cycles of TMZ would be sufficient for achieving the survival gain.

In the updated report this year on the CATNON trial, concomitant TMZ was of no benefit for the whole study cohort, but for those with IDH mutated tumor, survival was improved. They also found that it was those with IDHmut tumor that had the survival advantage of the adjuvant treatment. The IDH mutated subgroup in the Neoadjuvant trial was small, thereby not allowing for firm conclusions. 


\section{Paper III}

An analysis of what methodologies and cut-offs regarding MGMT methylation status that are used worldwide in the clinic for glioma patients is reported. These data are compiled from the results of an international survey.

The methylation status of the promoter of the DNA repair gene $M G M T\left(O^{6}\right.$-methylguanine DNA methyltransferase) is the best predictive marker for treatment with alkylating agents, where today TMZ is the main compound used. The promoter region of the MGMT gene contains $97 \mathrm{CpG}$ sites that have different importance for gene silencing.

Several methods for determining MGMT status are available that can result in conflicting conclusions regarding the methylation status of the same tumor.

To better understand current practices regarding determination of MGMT status in the clinic worldwide and to collect the views of those working in the field, we conducted an international survey. No previous publication has investigated clinical practice regarding MGMT testing internationally.

\begin{tabular}{|c|c|c|c|c|c|}
\hline Method & $\begin{array}{c}\text { Analyzes } \\
\text { CpG's }\end{array}$ & $\begin{array}{l}\text { Number } \\
\text { of CpG's }\end{array}$ & $\begin{array}{l}\text { Bisulfite } \\
\text { treatment }\end{array}$ & Pros & Cons \\
\hline Pyrosequencing & Yes & $\leq 16$ & Yes & $\begin{array}{l}\text { Best predictive } \\
\text { value, good } \\
\text { reproducibility, high } \\
\text { sensitivity }\end{array}$ & $\begin{array}{l}\text { Not validated in } \\
\text { randomized trials }\end{array}$ \\
\hline MsPCR & Yes & $\begin{array}{l}\text { Multiple } \\
(\approx 8-12)\end{array}$ & Yes & $\begin{array}{l}\text { Validated in several } \\
\text { randomized trials }\end{array}$ & $\begin{array}{c}\text { Poor reliability in FFPE } \\
\text { tissue }\end{array}$ \\
\hline $\begin{array}{l}\text { Sanger } \\
\text { sequencing }\end{array}$ & Yes & $>16$ & Yes & Quantitative & $\begin{array}{l}\text { Not validated in } \\
\text { randomized trials }\end{array}$ \\
\hline $\begin{array}{l}\text { Illumina } 450 \mathrm{k} \text { or } \\
850 \mathrm{k} \text { whole } \\
\text { genome } \\
\text { methylation } \\
\text { assay }\end{array}$ & Yes & $\begin{array}{l}450000 / \\
850000\end{array}$ & Yes & $\begin{array}{l}\text { Focuses on DMR1 } \\
\text { and DMR2, reliable } \\
\text { for FFPE tissue }\end{array}$ & $\begin{array}{l}\text { High cost, long } \\
\text { turnaround time }\end{array}$ \\
\hline $\begin{array}{l}\text { Melting curve } \\
\text { analysis }\end{array}$ & No & 0 & Yes & High reproducibility & $\begin{array}{l}\text { Needs further } \\
\text { evaluation }\end{array}$ \\
\hline MS-MPLA & Yes & $\begin{array}{l}\text { Multiple } \\
(\approx 2-6)\end{array}$ & No & Non-bisulfite & $\begin{array}{l}\text { CpG must contain Hhal } \\
\text { restriction site GCGC }\end{array}$ \\
\hline $\begin{array}{l}\text { Immuno- } \\
\text { histochemistry }\end{array}$ & No & 0 & No & $\begin{array}{l}\text { Enables focus on } \\
\text { high cellularity } \\
\text { tumor areas }\end{array}$ & $\begin{array}{c}\text { Poor reproducibility / } \\
\text { high interobeserver } \\
\text { variability }\end{array}$ \\
\hline $\begin{array}{l}\text { MGMT mRNA } \\
\text { absolute value }\end{array}$ & No & 0 & No & Non-bisulfite & $\begin{array}{c}\text { Poor quality with FFPE } \\
\text { Needs special handling } \\
\text { of fresh tissue at } \\
\text { surgery }\end{array}$ \\
\hline
\end{tabular}

Table 3. Pros and Cons of different methods for analyses of MGMT methylation status. References ${ }^{47-50,52-55,108-110}$ 
The survey focused on which patients have tumor tissue tested for MGMT, the method used and the reason for choosing the specific method. We inquired about how the cut-off for methylated versus unmethylated tumor is defined and asked for comments regarding MGMT testing in general. Last we asked about opinions regarding international consensus guidelines for MGMT analyses.

The survey was answered by 152 respondents, mainly neuropathologist, from 25 countries.

Tumor tissue was reported by $37 \%$ to be analyzed for all GBM patients and by $35 \%$ for all gliomas after primary surgery. As apprehended, the results confirmed the use of a number of different techniques to determine methylation status. The methods most often reported were pyrosequencing and methylation specific PCR (msPCR). For those analyzing CpG islands, the number varied from 1-3 to $>16$. Other techniques were melting curve analysis, Sanger sequencing, Illumina methylation microarray platforms together with or without the DKFZ bioinformatic classifier, MS-MLPA (methylation-specific multiplex ligation-dependent probe amplification), immunohistochemistry (IHC), and MGMT mRNA absolute value ${ }^{48,108-110}$. For pros and cons, see table 3.

Problems identified relate to choice of CpGs, how to compare different methods, how to calculate methylation status and necessary methylation levels for response to TMZ (Figures 8 and 9).

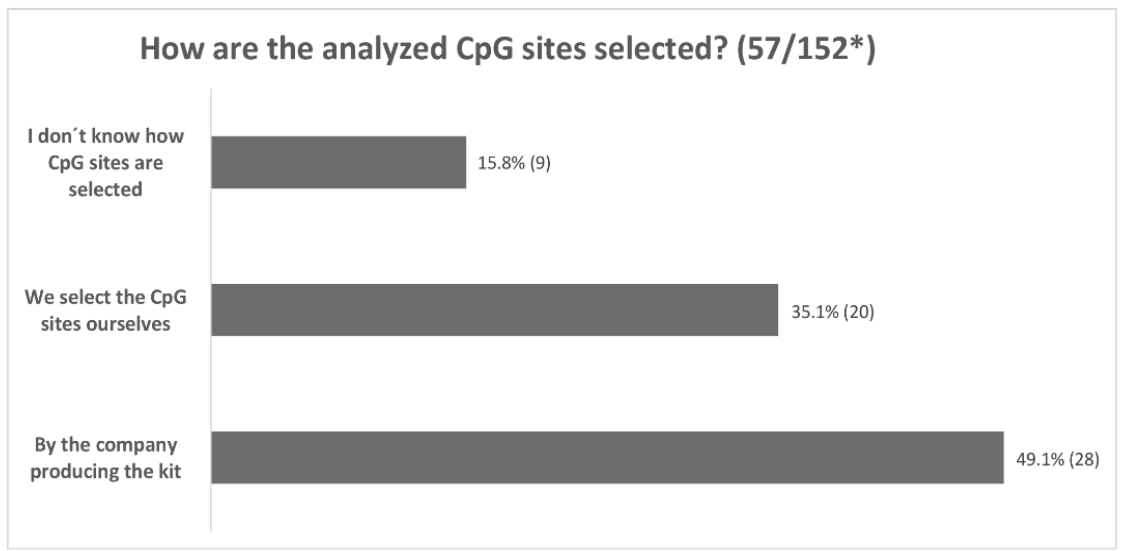

Figure 8. Results of question regarding how the analyzed CpG sites are selected.

*Number of responses/number of respondents

An additional crucial aspect identified by the respondents is the tumor cell content contra normal cells necessary in the tissue examined for correct assessment of tumor MGMT, which needs to be defined. Tumor heterogeneity also needs to be addressed. 
Some respondents suggested that tumors with borderline methylation should be reexamined with an additional method, to better be able to decide if it is methylated or not.

The majority of respondents to the survey acknowledge the mentioned difficulties for correctly defining MGMT methylation status in the clinic. They would like to see international guidelines for both methods and cut-off (Figures 10 and 11.).

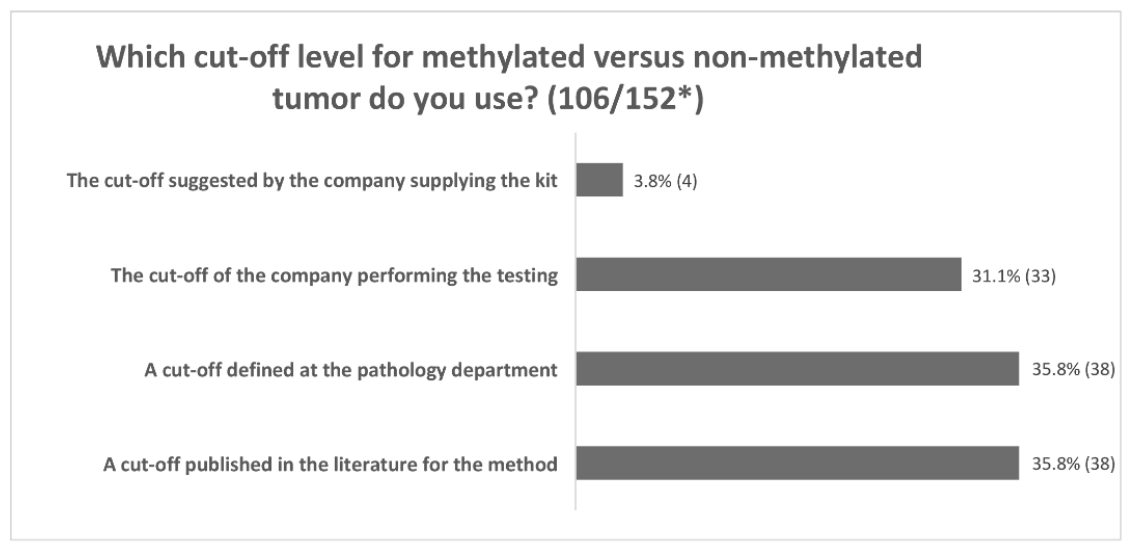

Figure 9. Results of question regarding which cut-off for methylated versus unmethylated $M G M T$ that is used. *Number of responses/number of respondents

One shortcoming of this study is that we do not know how many persons received the electronic survey. It could also be considered a limitation that for the one third of respondent who send their samples to an outside laboratory, the method for MGMT analysis was not requested. On the other hand, it is not certain that this method would be known. Additionally, due to a misunderstanding, methylation profiling was specified as methylation microarray, non-bisulfite, despite this being a method requiring bisulfite pretreatment. This could have caused uncertainty, but was possibly compensated for as respondents could report additional methods that they use. This was also the case, as a couple of respondents reported the use of the Illumina $450 \mathrm{k}$ or $850 \mathrm{k}$ methylation platform.

As the survey was sent to a number of Neuropathology associations, that then forwarded the survey to their members, we do not know the proportion of members answering the survey. We presume that those responding are mainly those actively involved in MGMT analyses and therefore contribute with their experience. The responses provide a picture of different methodologies, cut-offs and problems identified by those answering the survey. It cannot be ruled out that this list could have been even longer if we had received additional responses. One of the most important conclusions of this publication is the wish from the international community of those conducting MGMT analyses, to have international guidelines. To achieve this, it can be expected to necessitate an intensified international collaboration. 


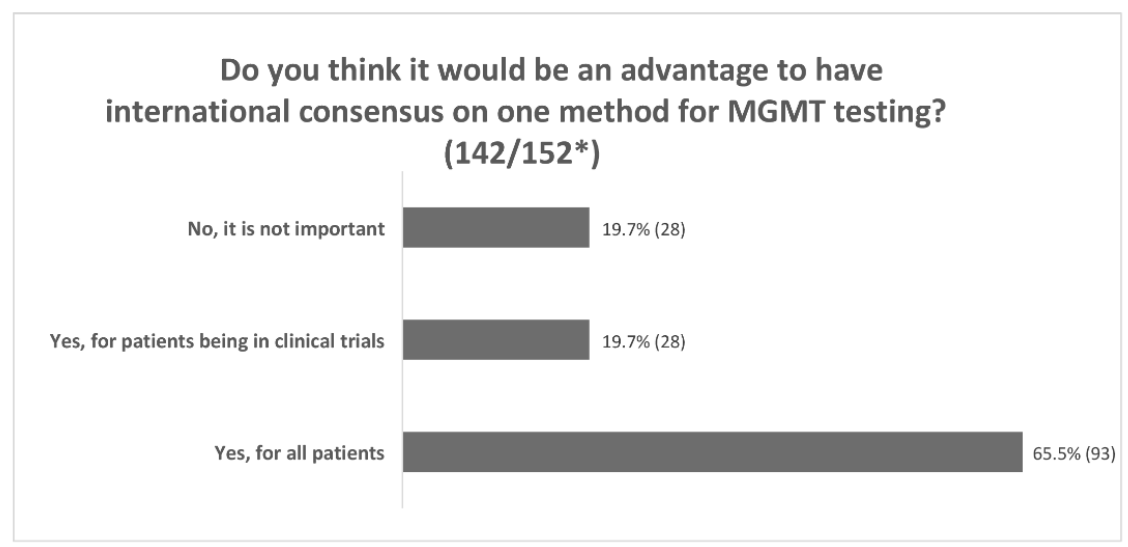

Figure 10. Results of question regarding international consensus guidelines for method.

*Number of responses/number of respondents

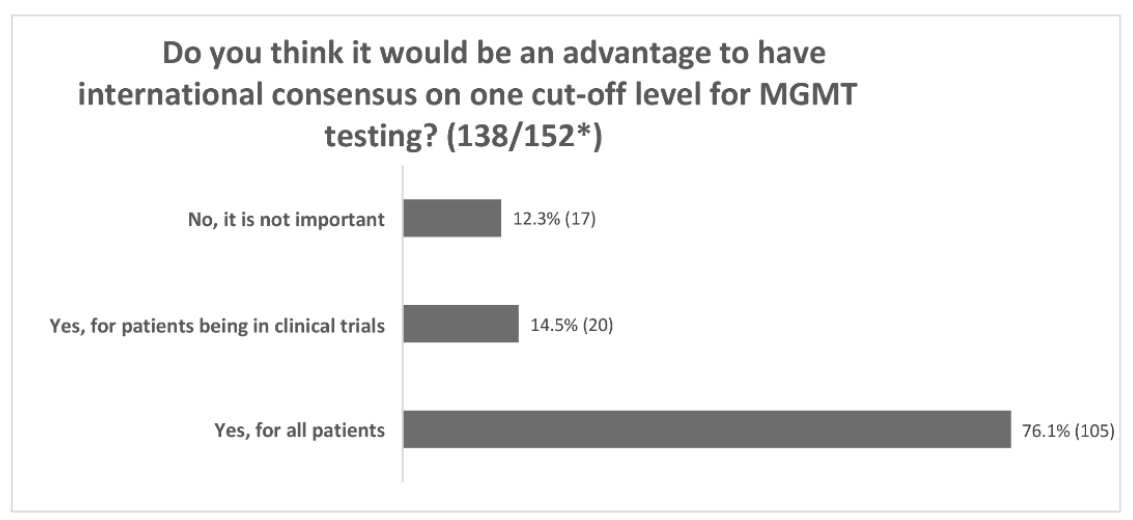

Figure 11. Results of question regarding international consensus guidelines for cut-off level.

*Number of responses/number of respondents

Guidelines would probably need to be developed in several steps, to allow for evaluation and further study of the issues mentioned above including comparison of different methods. 
Further, the study identifies a need to better define the clinically relevant cut-off for $M G M T$ methylated tumor for response to TMZ and for unmethylated tumor, for which patients TMZ therapy could safely be withheld.

Currently the EANO guidelines from 2017 for patients with GBM being > 70 years old prescribe single modality treatment with HRT for those with unmethylated tumor, while those with methylated $M G M T$ are recommended TMZ alone or in combination with $\mathrm{RT}^{8}$. In reality, the results from the survey suggest, as many report the analysis of MGMT status in larger patients groups, that $M G M T$ methylation status is incorporated into clinical decision making even for patients outside those defined in the EANO guidelines. 


\section{Conclusions \\ Paper I}

The NORDIC trial answered the initial study questions about optimal treatment for the comparison TMZ versus 60 Gy versus 34 Gy RT for patients 60 years or older with GBM. The study identified that survival with TMZ in standard dosing was better than with 60 Gy RT over 6 weeks. For patients $>70$ years even HRT to 34 Gy over 2 weeks was better than 60 Gy RT. Additionally, QoL measures favored TMZ treatment. To achieve the positive effect of TMZ treatment, we could show that the tumor needs to have a methylated MGMT promoter, which was not the case for response to RT.

\section{Paper II}

In the Neoadjuvant trial we could conclude that TMZ for 2-3 cycles after surgery before radiotherapy for a mixed patient cohort diagnosed with GBM or AA (with unknown molecular markers) does not confer a survival advantage as compared to SRT alone. In contrast, the subgroup of patients included as AA had a substantially prolonged survival with NeoTMZ. This finding, for AA patients, indicates that 2-3 cycles of TMZ might be sufficient for achieving the survival gain, as opposed to the 12 cycles in the CATNON trial. This warrants further study, preferably in a randomized trial.

For those with GBM, neoadjuvant treatment with TMZ for 2-3 months cannot be recommended, not even for those with methylated $M G M T$ promoter.

Subgroup analyses indicate the importance of molecular markers, especially IDH mutations and MGMT methylation status, for outcome, but warrant further confirmation. It seems likely that the negative outcome of NeoTMZ in GBM is correlated to IDHwt tumors, while the survival advantage of the same treatment in AA is due to IDH mutations.

Even though subgroup analyses are in line with previous findings, they are mainly hypothesis generating, and need to be interpreted with caution due to small numbers.

\section{Paper III}

In this study data were collected by an international survey, regarding the use of $M G M T$ methylation status analyses in the clinic. We identified that a number of different methods for analyzing MGMT are in use worldwide. There is neither a consensus on how the cut-off for methylated versus unmethylated tumor MGMT should be defined for different methods nor reliable knowledge of its correlation to response to alkylating agent treatment.

The respondents warrant international guidelines on both method and cut-off. 


\section{Concluding remarks}

For brain tumor patients a large number of projects and studies are ongoing nationally and internationally. While some investigate molecular aspects, others explore new therapies and still others focus on ways to improve the psychosocial care of glioma patients and their proxies. In different ways, they all aim at improving the care and outcome of those suffering of glioma.

Proton therapy is a relatively new treatment modality. It is expected that adverse events of this radiotherapy will be milder than for conventional RT, while its efficacy is expected to be equal $^{111}$. To date no randomized trials have been conducted. As a first step, treatment and outcome data of the more than 400 glioma patients treated in Sweden at the Skandion clinic will be reported in the PRO-CNS project (https://www.cancercentrum.se/samverkan/varauppdrag/forskning/cancerstudier-i-sverige/studier/pro-cns/\#Hjärna||||false). Planning of a phase III trial in collaboration between Sweden and Norway for patients with low-grade glioma is ongoing. A North American randomized phase II trial, NRG BN005, is accruing patients (https://www.mdanderson.org/patients-family/diagnosis-treatment/clinicaltrials/clinical-trials-index/clinical-trials-detail.IDNRG-BN005.html).

Immune therapy targeting programmed death 1 (PD-1), programmed death ligand 1 (PDL1) and/or programmed death ligand 2 (PD-L2) has been successful for several malignancies, such as melanoma and lung cancer ${ }^{12,113}$. Several trials have been conducted in GBM with nivolumab, a monoclonal antibody against PD-1, both in the recurrent setting and as an adjunct to standard of care in the primary setting for methylated and unmethylated tumor. Preliminary results have failed to show an advantage of nivolumab for $\mathrm{GBM}^{114}$. One explanation could be the relatively low mutational burden in GBM as compared to many other malignancies ${ }^{115}$. In an interesting paper by Costello et al, they discuss the effects of TMZ to cause a "hypermutated phenotype" in tumor recurrences. This occurs when the tumor is MGMT methylated and lacks intact MMR genes ${ }^{104,115}$. They hypothesize that this hypermutated tumor cell might be a functional target for immune therapy, as the mutational burden has been correlated to efficacy ${ }^{115}$. Another monoclonal antibody against PD-1, pembrolizumab, is currently being investigated for recurrent gliomas with hypermutator phenotype (NCT02658279) ${ }^{115}$.

In a Swedish trial another method to mobilize the immune system is investigated. Alecsat is an open, randomized phase II trial of immunotherapy as an adjunct to concomitant and adjuvant RT and TMZ. The patient's blood is used to activate cytotoxic T and NK cells, to boost the immune system. This study is in follow-up.

(https://www.cancercentrum.se/samverkan/vara-uppdrag/forskning/cancerstudier-isverige/studier/cv006-studien/)

For patients with progressive GBM after primary treatment, as mentioned earlier, mainly nitrosourea compounds are in use, but have limited efficacy ${ }^{8}$. Direct is a Swedish randomized phase II/III trial for GBM patients, exploring the addition of Disulfiram to second line treatment with nitrosourea compounds at progression. Potential anti-glioma effects of disulfiram are believed to impact on MGMT, p-glycoprotein, invasion and glioma 
initiating cells ${ }^{116}$ (https://www.cancercentrum.se/samverkan/varauppdrag/forskning/cancerstudier-i-sverige/studier/direktstudien/\#Hjärna||||false).

The publication of the new WHO guidelines in Neuro-Pathology has been a huge step forward for the prognostication and treatment of patients with glioma ${ }^{4}$. As described in this thesis, the analyses of molecular markers, especially MGMT can be problematic and there is a need for improvement. An impressive effort is the methylation profiling of tumors by the Illumina platform investigating up to $850 \mathrm{~K}$ methylation sites throughout the genome. Results on glioma with this technique have been reported by the Heidelberg group. The results have been shown to classify tumors of the central nervous system with great certainty and help to diagnose equivocal cases ${ }^{30,31}$. The methylation status of MGMT will be evaluated in parallel. Up to date the cons are though the availability, the high cost and the turnaround time. In the future hopefully this approach will be readily available, thereby providing detailed information on the molecular profile of each tumor. This can be expected to facilitate prognostication and treatment prediction.

The ongoing meta-analysis of the elderly trials ${ }^{40}$ in collaboration with the EORTC, German Neuro-oncology group $\mathrm{NOA}^{42}$ and the Canadian $\mathrm{NCIC}^{43}$ mentioned earlier, is expected to soon provide clinically relevant information for better treatment recommendations for GBM patients in this age group.

Two ongoing international trials have been described in this thesis, the CATNON and CODEL. For the CATNON, investigating patients with AA without $1 \mathrm{p} / 19 \mathrm{q}$ codeletion, published preliminary data already propose that the addition of TMZ adjuvant for 12 cycles will prolong survival ${ }^{88}$. Preliminary data on the role of concomitant TMZ together with RT were presented at ASCO and EANO 2019 and molecular analysis confirms the importance of IDH mutations for outcome. MGTM data, when available for subgroups, will add further important information.

The CODEL trial made a halt after the publication of the long term results of combined treatment of patients with oligodendroglioma with $\mathrm{RT}$ and $\mathrm{PCV}^{57,70}$. It has been updated to focus on the question of adjuvant PCV or concomitant and adjuvant TMZ for patients with 1p/19q codeleted tumors, both grade II and III and will hopefully settle the debate regarding best practice ${ }^{29}$. Swedish centers will contribute to this trial.

A small but interesting trial by the German Neuro-Oncology group investigated the combination of TMZ and the nitrosourea agent Lomustine as primary treatment in MGMT methylated GBM in a randomized setting. A survival advantage was found for the combination with median survival being prolonged from 31 to 48 months $(p=0.043)^{117}$. This trial awaits further confirmation.

Without doubt, the majority of future therapeutic trials will include patients selected according to molecular profiling of their tumor. A larger effort of the EORTC in this direction is the SPECTA (Screening Patients for Efficient Clinical Trials Access) platform (https://www.eortc.org/specta). For this project, at surgery patients are asked to consent to tumor tissue being sent to a common biobank and to be analyzed by high-quality molecular and pathological screening for molecular targets. The aim is to facilitate patient selection into 
clinical trials. The results of testing are also made available to the patient and treating physician to aid clinical decisions. This project focuses on several malignancies and includes high-grade glioma.

The psychosocial wellbeing of the patients and their proxies is receiving legitimate increase in attention. PROM and PREM are investigated by surveys sent to patients registered in the $\mathrm{SNQR}^{1,118}$. For PROM this is after 3 and 12 months from surgery and for PREM after 7 months. PROM compiles data on QoL and mental fatigue, and PREM on the experiences of the quality of health care provided. The aim is to achieve an improvement of patient care and to provide a ground for research. Also work is ongoing with the aim to incorporate PROM in the consultations in the clinic in the near future.

The Swedish Brain Tumor Patient Association is very active and "Who Cares?" is a study initiated by this group. It is a research project by a $\mathrm{PhD}$ student, conducted in collaboration with the clinics treating brain tumor patients and the brain tumor patients association. Patients and proxies are asked to draw a "care map" of social relationships and are interviewed regarding experienced supportive care needs. The aims are to find ways to identify these needs in the clinic, to be able to better provide individually tailored support.

To conclude, treatment of patients with glioma needs to be personalized taking into account both patient related prognostic factors, such as age and performance status, the type of surgery performed and tumor related, such as diagnosis and molecular markers. Here a further evolution of individualized molecular medicine can be expected in the future, regarding both prognostic and predictive markers. Lastly, this information together with treatment recommendations needs to be discussed with the patient to the extent that he or she wishes, to allow for informed decision making. This can be expected to provide each patient with their best treatment strategy. 


\section{Acknowledgement}

I would like to express my gratitude to all those who made this work possible.

I need to begin with my thanks to my first head of the Oncology department at Linköping University Hospital, Lars Baldetorp, who one day told me he wanted me to take on the clinical responsibility for brain tumor patients. This was an area of oncology that I at the time knew rather little about. It was exciting to broaden my knowledge in the field and it still is! Thank you, Lars!

The next key person was Professor Roger Henriksson from Umeå. During the 90's he initiated the Swedish National Brain Tumor Group, which is still going strong! A study was initiated in those early days, testing a concept later shown to be successful with another drug. High grade glioma patients were randomized between standard 6 weeks radiotherapy and radiotherapy concomitant with Estramustine, shown by researchers in Umeå to be useful for treating glioma cells. Unfortunately the study, although showing a trend for better survival with the addition of Estramustine, had too few patients to reach statistical significance. I remember well, that Roger when introducing the study protocol, spoke about that next time maybe someone else had an idea for a national study!

In my clinical work I often met elderly patients with glioblastoma and through the collaborations within the national group became aware of that these patients were treated (or not treated!) very differently depending on the hospital they were referred to. Often their tumors were not even diagnosed by surgery after CT scans showing a picture of high grade glioma. The available literature stated that patients over 60 years had a very short expected survival of a couple of months. Those not offering tumor specific treatment (standard at the time being 6 weeks of radiotherapy) argued that this would compromise quality of life for the short remaining lifespan. Some treated patients with hypofractionated radiotherapy and felt that some patients survived unexpectedly long time. So who was doing "the right thing"? Those treating or not treating? And which treatment?

Roger was supportive when I presented the idea for a study protocol focusing on patients over 60 years with glioblastoma. The first plan was to compare standard radiotherapy with hypofractionated treatment versus a control arm with no treatment. We foresaw problems in accruing patients to the trial. At this time point, the end of the nineties, the first data on a new alkylating agent were published, being developed from DTIC, a commonly used drug for malignant melanoma patients. This new drug seemed to have an effect on glioma, were previously mainly nitrosourea compounds were available, having a limited impact. The company introducing this agent were positive. Roger was instrumental in this collaboration where the control arm of no treatment was altered to temozolomide. Little did we know at the time what the results of this would be! The number of participating centers could be increased from sole Swedish, by a Nordic collaboration being initiated. The Nordic Clinical Brain Tumor Study Group was born! Later on the EORTC were invited to participate and additional countries joined the trial. 
Roger was also the first person who often said: "This work can become a part of your thesis" referring to different projects throughout the years. Thank you, Roger!

He has always been flanked by his indispensable secretary, Monica Sandström. She has always been helpful and supportive whenever it has been needed- travel grants, conference meetings, you name it! Thank you, Monica!

The next key person is Marie Stenmark-Askmalm. During her training to become a specialist in Oncology, I was appointed as her mentor. Marie did not need much of a mentor. She had just finished her thesis and instead rather became my mentor regarding research. She was crucial in starting the brain tumor biobank. She always argued that I must write my thesis. When I started working at the Department of Advanced Home Care (LAH) it suddenly seemed like it might be possible. And not only that, Marie introduced me to Peter, which led to him accepting me as a $\mathrm{PhD}$ student. Thank you Marie for never giving up on me!

My co-supervisor and colleague Marit Karlsson, thank you for your patient focus! You never hesitated, when we "brain stormed" about a qualitative study to investigate the experiences and requests of patients with brain tumors! I believe this project to be important, so that we can further improve our support to brain tumor patients and their families! We should never forget for whom we are there! Thank you, Marit!

My supervisor, Professor Peter Söderkvist! I am extremely grateful for you accepting a new $\mathrm{PhD}$ student being in her 50's! I am sure you have had time to wonder many times during the last 10 years if you did the correct choice! You must sometimes have had second thoughts about what I was up to, when I embarked on a new exciting research project, but you have always been supportive! I greatly appreciate all your efforts and patients over the years! I have enjoyed all these years doing research together with you and your fantastic group! Thank you, Peter!

Special thanks to Malgorzata Lysiak, "Gosia" for handling all the samples, doing all the laboratory work, collaborating with other research groups and the pathology department and being so nice to work and visit conferences together with! Your input has been invaluable! Many thanks also to the rest of the group working on the projects: Anette Molbaek, Åsa Schippert, Naomi Yamada-Fowler, and Lena Thunell. I also wish to acknowledge all the Polish Erasmus students who spent time in the lab working on the brain tumor projects. Thank you to Ravi Kumar Dutta, Hugo Mario Rossitti, Mouna Tababi and all the others on the $9^{\text {th }}$ floor! You have all made me feel like a part of the "family"! I have enjoyed the Christmas party every year!

My colleagues and friends from the South-East Region of Sweden have been important for many projects and we have spent many meetings and conferences together. They all never fail to have a patient focus and to be interested in research and developing better treatments and support to those suffering from a brain tumor and their families. I am fortunate to be your colleague! Thank you, Peter Milos, Munire Mudaisi, Charlotte Bratthäll, Michael Strandeus and Helena Bruhn! 
I also want to thank the statisticians, whom without no thesis would have been written! Thank you for your patients in looking at the data to try to answer all my endless questions and still be firm with what cannot be answered! Thank you Johan Rosell and Lisa Åkesson from the Regional Cancer Center South-East Sweden, Region Östergötland and also a separate thank you to John Carstensen, who helped me with the statistics for the protocol of the Nordic trial and was supportive at the final analysis! Thank you to Björn Tavelin, statistician at the Regional Cancer Centre in Umeå, for the analyses of the quality of life data of the Nordic trial and for data from the Swedish National Quality Registry!

“Tissue is the issue!" I therefore need to express my gratitude to Martin Hallbeck, head of the Pathology Department, Linköping University Hospital, together with Angeliki

Papagiannopoulou and many others, preparing tissue and DNA for analyses. Also thank you to all those pathology departments over Sweden, Scandinavia and Europe who sent the tissue of the patients in the studies for analyses! A very special thank you to Bjarne Winther Kristensen, co-author of two of the publications in this thesis. I appreciate your genuine interest in working together with other researchers in neuro-oncology and I am very happy for our collaboration.

During the years with the Swedish National Brain Tumor Group and the Nordic Clinical Brain Tumor Study Group I have worked together with many people deeply dedicated to patients with brain tumors. I have appreciated these collaborations and many I consider my friends. I would like to thank all of them and especially Anja Smits, Sara Kinhult, Katja Werlenius, Bjørn-Henning Grønberg, Hans Skovgaard Poulsen and Hanna Mäenpää.

For international collaborators I would like to thank Thierry Gorlia, statistician of the EORTC:s brain tumor group, Roger Stupp, inventor of the concomitant and adjuvant temozolomide treatment and collaborator in the Nordic trial, Monika Hegi for support regarding many molecular projects and especially important for arranging the review of the diagnosis and MGMT analyses for the Nordic trial. A special thank you to Benoit Lhermitte, in Lausanne for conducting the pathology review for this trial with short notice. Thank you also to Christine Marosi, Didier Frappaz and Ufuk Abacioglu, all collaborators in the Nordic trial. My gratitude to Martin van den Bent, colleague in the EORTC brain tumor group, for sharing his knowledge and slides on many occasions!

I also thank all my co-authors not already mentioned, Elizabeth Hovey, Henrik Schultz, Giuseppe Stragliotto, Steinbjørn Hansen, Thomas Asklund, Birgitta Holmlund and Joseph Dowsett.

I am indebted to the Department of Advanced Home Care, where I am employed. First I need to thank Gunnar Carlgren, who saw a value of my research in brain tumors despite this not directly focusing on palliative care and Niclas Hilding after him, both supporting with generous amounts of research time! I need to thank all my colleagues, Åsa Nord, Thomas Blystad, Waldemar Bau, Ruth Jose Zomorodian, Jacqueline Mudra, Bärbel Martin, Anna Bergendahl Sandstedt, Anna Ighe Ramqvist and Olivera Poljakovic who have taken care of all the patients during many weeks when I have been away from work doing research. Thank you to all of you! Looking forward to seeing more of you soon! 
I need to thank all patients who consented to taking part in the studies and all staff that were involved in the trials. My thanks also to the neuropathologists and others who shared their experiences and proposals for improvement of molecular testing.

I want to thank those organizations that have supported the research in this thesis with grants, the South-East Sweden FORSS research grant, LiUCancer, NSC research grant, The Swedish Cancer Society, the County Council of Östergötland, a research grant from Linköping University Hospital for Neuro-research, Lion's Cancer Foundation and Cancer Foundation Norrland, Umeå and Rotary Borgholm research grant.

Last, but not least, I want to thank my family, Bosse and Kasper. Kasper lay in my lap as a newborn baby, when I was writing the study protocol of the Nordic elderly trial! Now, when I am defending my thesis including this study, he is 20 ! 


\section{References}

1. Nationellt kvalitetsregister för hjärntumörer Nationell rapport 1999-2017 september 2018. Regionala Cancercentrum i Samverkan;2018.

2. Cancer i siffror 2018 Populärvetenskapliga fakta om cancer. Socialstyrelsen Cancerfonden;2018.

3. Cavers D, Hacking B, Erridge SC, Morris PG, Kendall M, Murray SA. Adjustment and support needs of glioma patients and their relatives: serial interviews. Psychooncology. Jun 2013;22(6):1299-1305.

4. Louis DN, Perry A, Reifenberger G, et al. The 2016 World Health Organization Classification of Tumors of the Central Nervous System: a summary. Acta neuropathologica. Jun 2016;131(6):803-820.

5. Stupp R, Mason WP, van den Bent MJ, et al. Radiotherapy plus concomitant and adjuvant temozolomide for glioblastoma. The New England journal of medicine. Mar 10 2005;352(10):987-996.

6. Pretanvil JA, Salinas IQ, Piccioni DE. Glioblastoma in the elderly: treatment patterns and survival. CNS Oncol. Jan 2017;6(1):19-28.

7. Claus EB, Walsh KM, Wiencke JK, et al. Survival and low-grade glioma: the emergence of genetic information. Neurosurg Focus. Jan 2015;38(1):E6.

8. Weller M, van den Bent M, Tonn JC, et al. European Association for Neuro-Oncology (EANO) guideline on the diagnosis and treatment of adult astrocytic and oligodendroglial gliomas. The lancet oncology. Jun 2017;18(6):e315-e329.

9. Malmer B, Gronberg H, Bergenheim AT, Lenner P, Henriksson R. Familial aggregation of astrocytoma in northern Sweden: an epidemiological cohort study. International journal of cancer. Journal international du cancer. May 5 1999;81(3):366-370.

10. Sadetzki S, Bruchim R, Oberman B, et al. Description of selected characteristics of familial glioma patients - results from the Gliogene Consortium. Eur J Cancer. Apr 2013;49(6):13351345.

11. Ostrom QT, Gittleman H, Stetson L, Virk S, Barnholtz-Sloan JS. Epidemiology of Intracranial Gliomas. Prog Neurol Surg. 2018;30:1-11.

12. Labreche K, Kinnersley B, Berzero G, et al. Diffuse gliomas classified by 1p/19q co-deletion, TERT promoter and IDH mutation status are associated with specific genetic risk loci. Acta neuropathologica. May 2018;135(5):743-755.

13. Fyllingen EH, Hansen TI, Jakola AS, Haberg AK, Salvesen O, Solheim O. Does risk of brain cancer increase with intracranial volume? A population-based case control study. Neurooncology. Aug 2 2018;20(9):1225-1230.

14. Weinberg RA. The biology of cancer. New York: Garland Science; 2007.

15. Hanahan D, Weinberg RA. Hallmarks of cancer: the next generation. Cell. Mar 4 2011;144(5):646-674.

16. Lee JH, Lee JE, Kahng JY, et al. Human glioblastoma arises from subventricular zone cells with low-level driver mutations. Nature. Aug 2018;560(7717):243-247.

17. Waitkus MS, Diplas BH, Yan H. Isocitrate dehydrogenase mutations in gliomas. Neurooncology. Jan 2016;18(1):16-26.

18. Malta TM, de Souza CF, Sabedot TS, et al. Glioma CpG island methylator phenotype (GCIMP): biological and clinical implications. Neuro-oncology. 2017;20(5):608-620.

19. Reifenberger J, Reifenberger G, Liu L, James CD, Wechsler W, Collins VP. Molecular genetic analysis of oligodendroglial tumors shows preferential allelic deletions on 19q and 1p. The American journal of pathology. Nov 1994;145(5):1175-1190.

20. Cairncross JG, Ueki K, Zlatescu MC, et al. Specific genetic predictors of chemotherapeutic response and survival in patients with anaplastic oligodendrogliomas. Journal of the National Cancer Institute. Oct 7 1998;90(19):1473-1479. 
21. Cahill DP, Louis DN, Cairncross JG. Molecular background of oligodendroglioma: 1p/19q, IDH, TERT, CIC and FUBP1. CNS Oncol. 2015;4(5):287-294.

22. Appin CL, Brat DJ. Molecular pathways in gliomagenesis and their relevance to neuropathologic diagnosis. Adv Anat Pathol. Jan 2015;22(1):50-58.

23. Brennan CW, Verhaak RG, McKenna A, et al. The somatic genomic landscape of glioblastoma. Cell. Oct 10 2013;155(2):462-477.

24. Sottoriva A, Spiteri I, Piccirillo SG, et al. Intratumor heterogeneity in human glioblastoma reflects cancer evolutionary dynamics. Proceedings of the National Academy of Sciences of the United States of America. Mar 5 2013;110(10):4009-4014.

25. Louis DN, Ohgaki H, Wiestler OD, et al. The 2007 WHO classification of tumours of the central nervous system. Acta neuropathologica. Aug 2007;114(2):97-109.

26. van den Bent MJ. Interobserver variation of the histopathological diagnosis in clinical trials on glioma: a clinician's perspective. Acta neuropathologica. Sep 2010;120(3):297-304.

27. Asklund T, Malmstrom A, Bergqvist M, Bjor O, Henriksson R. Brain tumors in Sweden: data from a population-based registry 1999-2012. Acta Oncol. Mar 2015;54(3):377-384.

28. Shirahata $M$, Ono T, Stichel D, et al. Novel, improved grading system(s) for IDH-mutant astrocytic gliomas. Acta neuropathologica. Jul 2018;136(1):153-166.

29. Ruff MW, Buckner JC, Johnson DR, van den Bent MJ, Geurts M. Neuro-Oncology Clinical Debate: PCV or temozolomide in combination with radiation for newly diagnosed high-grade oligodendroglioma. Neurooncol Pract. Jan 2019;6(1):17-21.

30. Capper D, Stichel D, Sahm F, et al. Practical implementation of DNA methylation and copynumber-based CNS tumor diagnostics: the Heidelberg experience. Acta neuropathologica. Aug 2018;136(2):181-210.

31. Capper D, Jones DTW, Sill M, et al. DNA methylation-based classification of central nervous system tumours. Nature. Mar 22 2018;555(7697):469-474.

32. Jenkins RB, Blair H, Ballman KV, et al. A t(1;19)(q10;p10) mediates the combined deletions of $1 p$ and $19 q$ and predicts a better prognosis of patients with oligodendroglioma. Cancer Res. Oct 15 2006;66(20):9852-9861.

33. Hoang-Xuan K, Capelle L, Kujas M, et al. Temozolomide as initial treatment for adults with low-grade oligodendrogliomas or oligoastrocytomas and correlation with chromosome $1 \mathrm{p}$ deletions. Journal of clinical oncology : official journal of the American Society of Clinical Oncology. Aug 1 2004;22(15):3133-3138.

34. Baumert BG, Hegi ME, van den Bent MJ, et al. Temozolomide chemotherapy versus radiotherapy in high-risk low-grade glioma (EORTC 22033-26033): a randomised, open-label, phase 3 intergroup study. The lancet oncology. Nov 2016;17(11):1521-1532.

35. Mosrati MA, Malmstrom A, Lysiak M, et al. TERT promoter mutations and polymorphisms as prognostic factors in primary glioblastoma. Oncotarget. Jun 30 2015;6(18):16663-16673.

36. Pekmezci M, Rice T, Molinaro AM, et al. Adult infiltrating gliomas with WHO 2016 integrated diagnosis: additional prognostic roles of ATRX and TERT. Acta neuropathologica. Jun 2017;133(6):1001-1016.

37. Reis GF, Pekmezci M, Hansen HM, et al. CDKN2A loss is associated with shortened overall survival in lower-grade (World Health Organization Grades II-III) astrocytomas. Journal of neuropathology and experimental neurology. May 2015;74(5):442-452.

38. Roodakker KR, Elsir T, Edqvist PD, et al. PROX1 is a novel pathway-specific prognostic biomarker for high-grade astrocytomas; results from independent glioblastoma cohorts stratified by age and IDH mutation status. Oncotarget. Nov 08 2016;7(45):72431-72442.

39. Hegi ME, Diserens AC, Gorlia T, et al. MGMT gene silencing and benefit from temozolomide in glioblastoma. The New England journal of medicine. Mar 10 2005;352(10):997-1003.

40. Malmstrom A, Gronberg BH, Marosi C, et al. Temozolomide versus standard 6-week radiotherapy versus hypofractionated radiotherapy in patients older than 60 years with 
glioblastoma: the Nordic randomised, phase 3 trial. The lancet oncology. Sep 2012;13(9):916-926.

41. Malmstrom A, Poulsen HS, Gronberg BH, et al. Postoperative neoadjuvant temozolomide before radiotherapy versus standard radiotherapy in patients 60 years or younger with anaplastic astrocytoma or glioblastoma: a randomized trial. Acta Oncol. Dec 2017;56(12):1776-1785.

42. Wick W, Platten M, Meisner C, et al. Temozolomide chemotherapy alone versus radiotherapy alone for malignant astrocytoma in the elderly: the NOA-08 randomised, phase 3 trial. The lancet oncology. Jul 2012;13(7):707-715.

43. Perry JR, Laperriere N, O'Callaghan CJ, et al. Short-Course Radiation plus Temozolomide in Elderly Patients with Glioblastoma. The New England journal of medicine. Mar 16 2017;376(11):1027-1037.

44. van den Bent MJ, Erdem-Eraslan L, Idbaih A, et al. MGMT-STP27 methylation status as predictive marker for response to PCV in anaplastic Oligodendrogliomas and Oligoastrocytomas. A report from EORTC study 26951. Clinical cancer research : an official journal of the American Association for Cancer Research. Oct 1 2013;19(19):5513-5522.

45. Brown TJ, Brennan MC, Li M, et al. Association of the Extent of Resection With Survival in Glioblastoma: A Systematic Review and Meta-analysis. JAMA Oncol. Nov 1 2016;2(11):14601469.

46. Sancar F. Quick Uptakes: Sex-Specific Tumor Signatures Help Explain Differences in Glioblastoma Survival. JAMA : the journal of the American Medical Association. Mar 5 2019;321(9):824-825.

47. Mansouri A, Hachem LD, Mansouri S, et al. MGMT promoter methylation status testing to guide therapy for glioblastoma: refining the approach based on emerging evidence and current challenges. Neuro-oncology. Sep 52018.

48. Quillien V, Lavenu A, Karayan-Tapon L, et al. Comparative assessment of 5 methods (methylation-specific polymerase chain reaction, MethyLight, pyrosequencing, methylationsensitive high-resolution melting, and immunohistochemistry) to analyze 06-methylguanineDNA-methyltranferase in a series of 100 glioblastoma patients. Cancer. Sep 1 2012;118(17):4201-4211.

49. Tabatabai G, Stupp R, van den Bent MJ, et al. Molecular diagnostics of gliomas: the clinical perspective. Acta neuropathologica. Nov 2010;120(5):585-592.

50. Wick W, Weller M, van den Bent M, et al. MGMT testing--the challenges for biomarkerbased glioma treatment. Nat Rev Neurol. Jul 2014;10(7):372-385.

51. Weller M, Stupp R, Reifenberger G, et al. MGMT promoter methylation in malignant gliomas: ready for personalized medicine? Nat Rev Neurol. Jan 2010;6(1):39-51.

52. Costello JF, Futscher BW, Tano K, Graunke DM, Pieper RO. Graded methylation in the promoter and body of the 06-methylguanine DNA methyltransferase (MGMT) gene correlates with MGMT expression in human glioma cells. J Biol Chem. Jun 24 1994;269(25):17228-17237.

53. Everhard S, Tost J, El Abdalaoui $\mathrm{H}$, et al. Identification of regions correlating MGMT promoter methylation and gene expression in glioblastomas. Neuro-oncology. Aug 2009;11(4):348356.

54. Bady P, Sciuscio D, Diserens AC, et al. MGMT methylation analysis of glioblastoma on the Infinium methylation BeadChip identifies two distinct $\mathrm{CpG}$ regions associated with gene silencing and outcome, yielding a prediction model for comparisons across datasets, tumor grades, and CIMP-status. Acta neuropathologica. Oct 2012;124(4):547-560.

55. Malley DS, Hamoudi RA, Kocialkowski S, Pearson DM, Collins VP, Ichimura K. A distinct region of the MGMT CpG island critical for transcriptional regulation is preferentially methylated in glioblastoma cells and xenografts. Acta neuropathologica. May 2011;121(5):651-661. 
56. Cairncross JG, Wang M, Jenkins RB, et al. Benefit from procarbazine, lomustine, and vincristine in oligodendroglial tumors is associated with mutation of IDH. Journal of clinical oncology : official journal of the American Society of Clinical Oncology. Mar 10 2014;32(8):783-790.

57. van den Bent MJ, Brandes AA, Taphoorn MJ, et al. Adjuvant procarbazine, lomustine, and vincristine chemotherapy in newly diagnosed anaplastic oligodendroglioma: long-term follow-up of EORTC brain tumor group study 26951. Journal of clinical oncology : official journal of the American Society of Clinical Oncology. Jan 20 2013;31(3):344-350.

58. Cheng W, Ren X, Cai J, et al. A five-miRNA signature with prognostic and predictive value for MGMT promoter-methylated glioblastoma patients. Oncotarget. Oct 6 2015;6(30):2928529295.

59. Green H, Soderkvist P, Rosenberg P, Horvath G, Peterson C. ABCB1 G1199A polymorphism and ovarian cancer response to paclitaxel. Journal of pharmaceutical sciences. Jun 2008;97(6):2045-2048.

60. Stupp R, Taillibert S, Kanner A, et al. Effect of Tumor-Treating Fields Plus Maintenance Temozolomide vs Maintenance Temozolomide Alone on Survival in Patients With Glioblastoma: A Randomized Clinical Trial. JAMA : the journal of the American Medical Association. Dec 19 2017;318(23):2306-2316.

61. Stummer W, Pichlmeier U, Meinel T, et al. Fluorescence-guided surgery with 5aminolevulinic acid for resection of malignant glioma: a randomised controlled multicentre phase III trial. The lancet oncology. May 2006;7(5):392-401.

62. Pichlmeier U, Bink A, Schackert G, Stummer W, Group ALAGS. Resection and survival in glioblastoma multiforme: an RTOG recursive partitioning analysis of ALA study patients. Neuro-oncology. Dec 2008;10(6):1025-1034.

63. Vuorinen V, Hinkka S, Farkkila M, Jaaskelainen J. Debulking or biopsy of malignant glioma in elderly people - a randomised study. Acta Neurochir (Wien). Jan 2003;145(1):5-10.

64. Walker MD, Green SB, Byar DP, et al. Randomized comparisons of radiotherapy and nitrosoureas for the treatment of malignant glioma after surgery. The New England journal of medicine. Dec 4 1980;303(23):1323-1329.

65. Ruben JD, Dally M, Bailey M, Smith R, McLean CA, Fedele P. Cerebral radiation necrosis: incidence, outcomes, and risk factors with emphasis on radiation parameters and chemotherapy. International journal of radiation oncology, biology, physics. Jun 1 2006;65(2):499-508.

66. Dhermain F, Barani IJ. Complications from radiotherapy. Handb Clin Neurol. 2016;134:219234.

67. Tumörer i hjärna och ryggmärg Nationellt vårdprogram. 2 ed. https://www.cancercentrum.se/.../hjarna-och-ryggmarg/vardprogram2018.

68. Stupp R, Dietrich PY, Ostermann Kraljevic S, et al. Promising survival for patients with newly diagnosed glioblastoma multiforme treated with concomitant radiation plus temozolomide followed by adjuvant temozolomide. Journal of clinical oncology : official journal of the American Society of Clinical Oncology. Mar 1 2002;20(5):1375-1382.

69. van den Bent MJ. Practice changing mature results of RTOG study 9802: another positive PCV trial makes adjuvant chemotherapy part of standard of care in low-grade glioma. Neurooncology. Dec 2014;16(12):1570-1574.

70. Cairncross G, Wang M, Shaw E, et al. Phase III trial of chemoradiotherapy for anaplastic oligodendroglioma: long-term results of RTOG 9402. Journal of clinical oncology : official journal of the American Society of Clinical Oncology. Jan 20 2013;31(3):337-343.

71. Wick W, Hartmann C, Engel C, et al. NOA-04 randomized phase III trial of sequential radiochemotherapy of anaplastic glioma with procarbazine, lomustine, and vincristine or temozolomide. Journal of clinical oncology : official journal of the American Society of Clinical Oncology. Dec 10 2009;27(35):5874-5880. 
72. Wick W, Roth P, Hartmann C, et al. Long-term analysis of the NOA-04 randomized phase III trial of sequential radiochemotherapy of anaplastic glioma with PCV or temozolomide. Neuro-oncology. Nov 2016;18(11):1529-1537.

73. Silginer $M$, Weller $M$, Stupp R, Roth $P$. Biological activity of tumor-treating fields in preclinical glioma models. Cell Death Dis. Apr 20 2017;8(4):e2753.

74. Dubinski D, Hattingen E, Senft C, et al. Controversial roles for dexamethasone in glioblastoma - Opportunities for novel vascular targeting therapies. J Cereb Blood Flow Metab. Aug 2019;39(8):1460-1468.

75. Pitter KL, Tamagno I, Alikhanyan K, et al. Corticosteroids compromise survival in glioblastoma. Brain. May 2016;139(Pt 5):1458-1471.

76. Chinot OL, Wick W, Mason W, et al. Bevacizumab plus radiotherapy-temozolomide for newly diagnosed glioblastoma. The New England journal of medicine. Feb 20 2014;370(8):709-722.

77. Wick W, Gorlia T, Bendszus M, et al. Lomustine and Bevacizumab in Progressive Glioblastoma. The New England journal of medicine. Nov 16 2017;377(20):1954-1963.

78. Kaley T, Nolan C, Carver A, Omuro A. Bevacizumab for acute neurologic deterioration in patients with glioblastoma. CNS Oncol. Sep 2013;2(5):413-418.

79. Walker MD, Alexander E, Jr., Hunt WE, et al. Evaluation of BCNU and/or radiotherapy in the treatment of anaplastic gliomas. A cooperative clinical trial. J Neurosurg. Sep 1978;49(3):333-343.

80. Barani IJ, Larson DA. Radiation therapy of glioblastoma. Cancer treatment and research. 2015;163:49-73.

81. Keime-Guibert F, Chinot O, Taillandier L, et al. Radiotherapy for glioblastoma in the elderly. The New England journal of medicine. Apr 12 2007;356(15):1527-1535.

82. Gunjur A, Lau E, Taouk Y, Ryan G. Early post-treatment pseudo-progression amongst glioblastoma multiforme patients treated with radiotherapy and temozolomide: a retrospective analysis. J Med Imaging Radiat Oncol. Dec 2011;55(6):603-610.

83. Brandes AA, Franceschi E, Tosoni A, et al. MGMT promoter methylation status can predict the incidence and outcome of pseudoprogression after concomitant radiochemotherapy in newly diagnosed glioblastoma patients. Journal of clinical oncology : official journal of the American Society of Clinical Oncology. May 1 2008;26(13):2192-2197.

84. Park HH, Roh TH, Kang SG, et al. Pseudoprogression in glioblastoma patients: the impact of extent of resection. Journal of neuro-oncology. Feb 2016;126(3):559-566.

85. Meckling S, Dold O, Forsyth PA, Brasher P, Hagen NA. Malignant supratentorial glioma in the elderly: is radiotherapy useful? Neurology. Oct 1996;47(4):901-905.

86. Thomas R, James N, Guerrero D, Ashley S, Gregor A, Brada M. Hypofractionated radiotherapy as palliative treatment in poor prognosis patients with high grade glioma.

Radiotherapy and oncology : journal of the European Society for Therapeutic Radiology and Oncology. Nov 1994;33(2):113-116.

87. Chang S, Zhang P, Cairncross JG, et al. Phase III randomized study of radiation and temozolomide versus radiation and nitrosourea therapy for anaplastic astrocytoma: results of NRG Oncology RTOG 9813. Neuro-oncology. Feb 1 2017;19(2):252-258.

88. van den Bent MJ, Baumert B, Erridge SC, et al. Interim results from the CATNON trial (EORTC study 26053-22054) of treatment with concurrent and adjuvant temozolomide for 1p/19q non-co-deleted anaplastic glioma: a phase 3, randomised, open-label intergroup study. Lancet. Oct 7 2017;390(10103):1645-1653.

89. Jakola AS, Skjulsvik AJ, Myrmel KS, et al. Surgical resection versus watchful waiting in lowgrade gliomas. Annals of oncology : official journal of the European Society for Medical Oncology / ESMO. Aug 1 2017;28(8):1942-1948.

90. Karim AB, Maat B, Hatlevoll $R$, et al. A randomized trial on dose-response in radiation therapy of low-grade cerebral glioma: European Organization for Research and Treatment of 
Cancer (EORTC) Study 22844. International journal of radiation oncology, biology, physics. Oct 1 1996;36(3):549-556.

91. Shaw $E$, Arusell $R$, Scheithauer $B$, et al. Prospective randomized trial of low-versus high-dose radiation therapy in adults with supratentorial low-grade glioma: initial report of a North Central Cancer Treatment Group/Radiation Therapy Oncology Group/Eastern Cooperative Oncology Group study. Journal of clinical oncology : official journal of the American Society of Clinical Oncology. May 1 2002;20(9):2267-2276.

92. van den Bent MJ, Afra $D$, de Witte $O$, et al. Long-term efficacy of early versus delayed radiotherapy for low-grade astrocytoma and oligodendroglioma in adults: the EORTC 22845 randomised trial. Lancet. Sep 17-23 2005;366(9490):985-990.

93. Henderson $\mathrm{KH}$, Shaw EG. Randomized trials of radiation therapy in adult low-grade gliomas. Semin Radiat Oncol. Apr 2001;11(2):145-151.

94. Shaw EG, Wang M, Coons SW, et al. Randomized trial of radiation therapy plus procarbazine, lomustine, and vincristine chemotherapy for supratentorial adult low-grade glioma: initial results of RTOG 9802. Journal of clinical oncology : official journal of the American Society of Clinical Oncology. Sep 1 2012;30(25):3065-3070.

95. Gaston CM, Mitchell G. Information giving and decision-making in patients with advanced cancer: a systematic review. Soc Sci Med. Nov 2005;61(10):2252-2264.

96. Diamond EL, Corner GW, De Rosa A, Breitbart W, Applebaum AJ. Prognostic awareness and communication of prognostic information in malignant glioma: a systematic review. Journal of neuro-oncology. Sep 2014;119(2):227-234.

97. Diamond EL, Prigerson HG, Correa DC, et al. Prognostic awareness, prognostic communication, and cognitive function in patients with malignant glioma. Neuro-oncology. Oct 19 2017;19(11):1532-1541.

98. Innes S, Payne S. Advanced cancer patients' prognostic information preferences: a review. Palliative medicine. Jan 2009;23(1):29-39.

99. Goebel S, Mehdorn HM. Breaking Bad News to Patients with Intracranial Tumors: The Patients' Perspective. World Neurosurg. Oct 2018;118:e254-e262.

100. Henriksson R, Malmstrom A, Bergstrom P, et al. High-grade astrocytoma treated concomitantly with estramustine and radiotherapy. Journal of neuro-oncology. Jul 2006;78(3):321-326.

101. Bergenheim T, Malmstrom A, Bolander $\mathrm{H}$, et al. [Registration on regional basis of patients with primary brain tumors. Regional differences disclosed]. Lakartidningen. Jan 31-Feb 6 2007;104(5):332-338, 340-331.

102. Asklund T, Bjor O, Malmstrom A, Blomquist E, Henriksson R. [Survival in malignant gliomas has increased the last decade. Analysis of quality data]. Lakartidningen. Apr 25-May 8 2012;109(17-18):875-878.

103. Asklund T, Malmstrom A, Bjor O, Blomquist E, Henriksson R. Considerable improvement in survival for patients aged 60-84 years with high grade malignant gliomas -- data from the Swedish Brain Tumour Population-based Registry. Acta Oncol. Jun 2013;52(5):1041-1043.

104. van Thuijl HF, Mazor T, Johnson BE, et al. Evolution of DNA repair defects during malignant progression of low-grade gliomas after temozolomide treatment. Acta neuropathologica. Apr 2015;129(4):597-607.

105. Kirkwood BR, Sterne JAC. Essential medical statistics. 2nd ed. Malden, Mass.: Blackwell Science; 2003.

106. Roa W, Brasher PM, Bauman G, et al. Abbreviated course of radiation therapy in older patients with glioblastoma multiforme: a prospective randomized clinical trial. Journal of clinical oncology : official journal of the American Society of Clinical Oncology. May 1 2004;22(9):1583-1588.

107. Roa W, Kepka L, Kumar N, et al. International Atomic Energy Agency Randomized Phase III Study of Radiation Therapy in Elderly and/or Frail Patients With Newly Diagnosed 
Glioblastoma Multiforme. Journal of clinical oncology : official journal of the American Society of Clinical Oncology. Dec 10 2015;33(35):4145-4150.

108. Christians A, Hartmann C, Benner A, et al. Prognostic value of three different methods of MGMT promoter methylation analysis in a prospective trial on newly diagnosed glioblastoma. PLoS One. 2012;7(3):e33449.

109. Tanaka S, Akimoto J, Narita Y, Oka H, Tashiro T. Is the absolute value of O(6)-methylguanineDNA methyltransferase gene messenger RNA a prognostic factor, and does it predict the results of treatment of glioblastoma with temozolomide? J Neurosurg. Oct 2014;121(4):818826.

110. Kreth S, Thon N, Eigenbrod S, et al. O-methylguanine-DNA methyltransferase (MGMT) mRNA expression predicts outcome in malignant glioma independent of MGMT promoter methylation. PLoS One. Feb 18 2011;6(2):e17156.

111. Adeberg S, Harrabi SB, Verma V, et al. Treatment of meningioma and glioma with protons and carbon ions. Radiat Oncol. Dec 1 2017;12(1):193.

112. Wolchok JD, Chiarion-Sileni V, Gonzalez R, et al. Overall Survival with Combined Nivolumab and Ipilimumab in Advanced Melanoma. The New England journal of medicine. Oct 5 2017;377(14):1345-1356.

113. Reck M. Pembrolizumab as first-line therapy for metastatic non-small-cell lung cancer. Immunotherapy. Feb 2018;10(2):93-105.

114. Filley AC, Henriquez M, Dey M. Recurrent glioma clinical trial, CheckMate-143: the game is not over yet. Oncotarget. Oct 31 2017;8(53):91779-91794.

115. Choi S, Yu Y, Grimmer MR, Wahl M, Chang SM, Costello JF. Temozolomide-associated hypermutation in gliomas. Neuro-oncology. Sep 3 2018;20(10):1300-1309.

116. Triscott J, Lee $\mathrm{C}$, Hu K, et al. Disulfiram, a drug widely used to control alcoholism, suppresses the self-renewal of glioblastoma and over-rides resistance to temozolomide. Oncotarget. Oct 2012;3(10):1112-1123.

117. Herrlinger U, Tzaridis T, Mack F, et al. Lomustine-temozolomide combination therapy versus standard temozolomide therapy in patients with newly diagnosed glioblastoma with methylated MGMT promoter (CeTeG/NOA-09): a randomised, open-label, phase 3 trial. Lancet. Feb 16 2019;393(10172):678-688.

118. Rosenlund $L D E$, Jakola A. Moving from clinician-defined to patient-reported outcome measures for survivors of high-grade glioma. Patient Related Outcome Measures. 2019;2019(10):267-276. 
11. Appendix

Paper I-III 


\section{Papers}

The papers associated with this thesis have been removed for copyright reasons. For more details about these see:

http://urn.kb.se/resolve?urn=urn:nbn:se:liu:diva-161677 



\section{FACULTY OF MEDICINE AND HEALTH SCIENCES}

Linköping University Medical Dissertations No. 1709, 2019 Department of Clinical and Experimental Medicine Division of Cell Biology

Linköping University

SE-581 83 Linköping, Sweden

www.liu.se

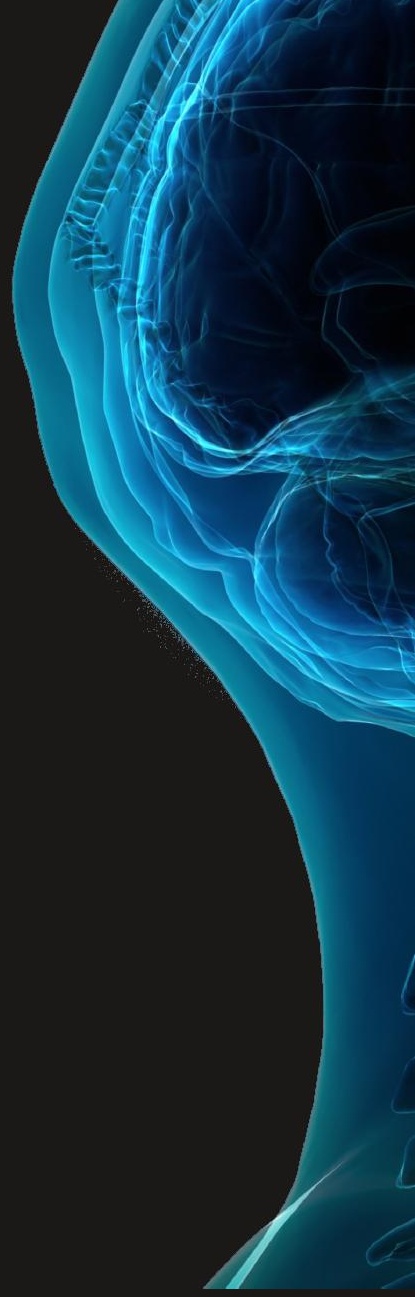

